IZA DP No. 10293

Collective Bargaining and the Evolution of Wage Inequality in Italy

Francesco Devicienti

Bernardo Fanfani

Agata Maida

October 2016 


\title{
Collective Bargaining and the Evolution of Wage Inequality in Italy
}

\author{
Francesco Devicienti \\ University of Turin, \\ Collegio Carlo Alberto and IZA
}

Bernardo Fanfani

University of Turin

Agata Maida

University of Milan

Discussion Paper No. 10293

October 2016

\author{
IZA \\ P.O. Box 7240 \\ 53072 Bonn \\ Germany \\ Phone: +49-228-3894-0 \\ Fax: +49-228-3894-180 \\ E-mail: iza@iza.org
}

Any opinions expressed here are those of the author(s) and not those of IZA. Research published in this series may include views on policy, but the institute itself takes no institutional policy positions. The IZA research network is committed to the IZA Guiding Principles of Research Integrity.

The Institute for the Study of Labor (IZA) in Bonn is a local and virtual international research center and a place of communication between science, politics and business. IZA is an independent nonprofit organization supported by Deutsche Post Foundation. The center is associated with the University of Bonn and offers a stimulating research environment through its international network, workshops and conferences, data service, project support, research visits and doctoral program. IZA engages in (i) original and internationally competitive research in all fields of labor economics, (ii) development of policy concepts, and (iii) dissemination of research results and concepts to the interested public.

IZA Discussion Papers often represent preliminary work and are circulated to encourage discussion. Citation of such a paper should account for its provisional character. A revised version may be available directly from the author. 


\section{ABSTRACT}

\section{Collective Bargaining and the Evolution of Wage Inequality in Italy*}

In this paper we study the evolution of the Italian wage inequality, and of its determinants, using two decades of matched employer-employee data covering the entire population of private-sector workers and firms in the Veneto region. We find that wage inequality has increased since the mid-1980s at a relatively fast pace, and we decompose this trend by means of wage regression models that account for both worker and firm fixed effects. We show that the observed and unobserved heterogeneity of the workforce has been a major determinant of the overall wage dispersion and of its evolution. Instead, we find that the importance of the dispersion in firm-specific wage policies has declined over time. Finally, we show that the growth in wage dispersion has almost entirely occurred between job titles (livelli di inquadramento) for which a set of minimum wages is bargained at the nation-wide sectoral level. We conclude that, even in the presence of the underlying market forces, trends in wage inequality have been channelled through the rules set by the country's fairly centralized system of industrial relations.

JEL Classification: J00, J5, J31, J40

Keywords: $\quad$ wage inequality, collective bargaining, two-way fixed effects, employer-employee data

Corresponding author:

Bernardo Fanfani

University of Turin

via Real Collegio 30

10024 Moncalieri (TO)

Italy

E-mail: bernardo.fanfani@unito.it

\footnotetext{
* We would like to thank David Card, Lia Pacelli, participants at the 2016 European Association of Labour Economists Conference, 2016 Conference of the European Society of Population Economics, and Collegio Carlo Alberto workshops for useful comments and feedbacks.
} 


\section{Introduction}

Wage inequalities have risen in most Western Countries during the last decades of the past century. Several hypotheses have been put forward to rationalize this secular trend. ${ }^{1}$ Some authors have pointed out that technological progress is largely responsible for the increased wage dispersion. A commonly held view is that advances in the production process may have led to a growth in the demand for skills that, due to demographic and schooling developments, outpaced their supply, eventually resulting in an increase of the returns to unevenly distributed workers' skills (e.g. Katz and Murphy [1992]). ${ }^{2}$ Instead, other theories state that changes in labour market institutions, such as declining minimum wages and union strength (e.g. Di Nardo, Fortin, and Lemieux [1996]), or changes in social norms (e.g Piketty and Saez [2003]) are the main drivers behind the observed secular rise in wage differentials.

More recently, several studies analysing matched worker-firm databases have pointed out that one important component of pay inequality is represented by differences in the wage policies between observationally similar firms (e.g. Abowd, Kramarz, and Margolis [1999]). Card, Heining, and Kline [2013] have recently shown that the firm-specific component of wage variation can explain up to one fourth of the wage variance increase that has occurred in West Germany between the late-1980s and the beginning of the new century. Moreover, they show that the sorting of high skilled workers into high-paying firms can account for another $30 \%$ of the variance increase. They attribute the rise in the dispersion of firms' wage premiums to the changes that have occurred in the wage bargaining system since the early 1990s. Indeed, during these years, and despite the prevalent role of industry-wide collective bargaining, German firms were given the possibility of opting-out from national contractual agreements, often resorting to establishment-level wage negotiations. Dust-

\footnotetext{
${ }^{1}$ For a recent review of the vast literature on wage inequality see Acemoglu and Autor [2011]. Due to limited data availability, most studies focus on the post-1970s inequality evolution. An assessment of long-run trends in income dispersion for several Western countries is provided by Piketty and Saez [2006].

${ }^{2} \mathrm{An}$ alternative hypothesis discussed in the literature, which is also related to technological progress, is that recent advances in the production process may have modified the demand for routine versus nonroutine based occupations. This process could have led to increased polarization of the wage structure (see for example Autor, Katz, and Kearney [2008]).
} 
mann, Fitzenberger, Schonberg, and Spitz-Oener [2014] argue that this decentralization in the wage setting process has been one of the main engines fostering the German economic growth during the last decade, since the new system has allowed to cut unit labour costs and to improve international competitiveness.

In this paper, we apply the methodology of Card, Heining, and Kline [2013] on Italian matched employer-employee data from administrative sources, which cover the entire population of private-sector workers and firms in the Veneto region. We study the evolution over time of the following components of pay dispersion: time-varying characteristics of the workforce, time-constant individual characteristics, firm-specific wage premiums, along with the contribution arising from the the correlation between each of these components. Moreover, we apply a related variance decomposition method, in order to test whether the growth in wage inequality has occurred mostly within or between the fine job title categories defined by the country's collective bargaining institutions.

An in-depth analysis of the Italian case is interesting in itself, but it also offers insights for evaluating the relevance of the various theories rationalizing the secular growth in wage inequality experienced elsewhere. Like other Western Countries, the Italian economy has been exposed to international competition and has experienced the challenges posed by the introduction of new technologies. The manufacturing sector is very large in Italy, and particularly in Veneto, ${ }^{3}$ a feature that makes its economy quite similar to the German one. Moreover, Italy is characterized by a wage setting mechanism highly centralized at the sector-wide level, which has not undergone the same renewal processes that characterized the German labour market during the 1990s.

Our analysis shows that Italian pay dispersion has grown at a similar pace than the German one during the period considered, even if Italy did not experience the same growth in firms' wage premiums dispersion that Card, Heining, and Kline [2013] document for Germany. The results suggest that the amount of wage flexibility at the firm level granted by the system has even reduced over time. Indeed, during the overall period considered,

\footnotetext{
${ }^{3}$ In Veneto, during the pre-2009 crisis years, the manufacturing sector represented around $30 \%$ of the total value added.
} 
Italian firms have been unable to opt-out, or diverge in any other significant way, from the wage dynamics settled within the relevant industry-wide collective agreements.

As we report below, a large proportion of the growth in earning dispersion over the entire period considered is attributed to raising heterogeneity (observed and unobserved) in the portable component of a worker's pay, namely the part of the wage attributable to individual-specific characteristics equally rewarded across employers. In principle, the raising contribution of workers' heterogeneity may simply reflect the underlying dynamics of supply and demand factors. However, we show that in practice this component of inequality is closely linked to the wage pay scales and seniority wage increments bargained at the industry level by the main union confederations and employers' associations. Hence, we tend to interpret the finding of rising workers' heterogeneity as yet another outcome induced by the Italian system of industrial relations, which seems to impose significant constraints on wage dynamics.

To substantiate our claim, we divide the variance of $(\log )$ wages and of workers' observed and unobserved heterogeneity into a within and a between job titles part. Job titles (called livelli di inquadramento in Italian) are occupations defined by the relevant sectoral collective agreements, for which a minimum wage applies regardless of a worker's union membership. We find that the growth in the between-variance component virtually explains the entire inequality trend observed in the data. To the best of our knowledge, this growing trend in the between job title dispersion of wages has never been so extensively documented before, partly owing to data limitations in past research on Italian wage inequality. ${ }^{4}$

Finally, we find that another important component of the wage inequality growth has been the increased positive sorting between firms' pay premiums and the human capital of the workforce. Despite the level of the correlation between these two components

\footnotetext{
${ }^{4} \mathrm{~A}$ nice feature of our data is that they contain job-title information for every worker in the sample. The datasets used in previous Italian studies, e.g. the Bank of Italy's Survey on Household Income and Wealth used by Manacorda [2004], do not contain individual-level information on livelli di inquadramento or, when they do, cover only a specific sector (metalworkers) and area (the province of Milan), e.g. Erickson and Ichino [1995]. Using Portuguese data, Torres, Portugal, Addison, and Guimaraes [2013] find that job title fixed effects in wage regressions explain around $10 \%$ of the total wage variance. However, they do not explicitly focus on the contribution of these effects in explaining the evolution of inequality in Portugal.
} 
is generally low in each time period, a clear increasing tendency emerges from our estimates. Although we were unable to present conclusive evidence on the determinants of such trend, it is tempting to associate greater assortative matching to the general labour market deregulation experienced by Italy during the last few decades. Indeed, during the overall period considered, the presence of trade unions at the firm level has been declining, a tendency which has reduced the overall amount of rent sharing, particularly among low skilled employees. Moreover, some of the 1980s and 1990s reforms, such as the liberalization of the hiring process, the weakening in employment protection legislation, the abolition of egalitarian practices embedded in the wage indexation mechanisms (i.e., the so-called Scala Mobile) and in the wage setting institutions, had the potential to undermine the bargaining power of workers at the bottom of the wage distribution and to reduce matching frictions. ${ }^{5}$

Our paper is connected to a (moderately-sized) literature that has previously studied the Italian wage distribution and its changes over time, using either social security data (see, among others, Cappellari [2004] and Leonardi, Pellizzari, and Tabasso [2015]) or earnings data collected in household surveys (e.g., Brandolini, Cipollone, and Sestito [2002], Manacorda [2004], Naticchioni and Ricci [2009]). Nevertheless, our use of the decomposition methodology proposed by Card, Heining, and Kline [2013] is entirely new in the Italian context. ${ }^{6}$ To the best of our knowledge, our finding of a negative contribution of the firm-specific wage premiums to the trends in overall wage inequality is also novel, and potentially interesting, beyond Italy.

The paper is organized as follows. In the next section, we review the existing evidence on the evolution of wage inequality in Italy, providing also a brief institutional framework. In Section 3, we describe the database and the sampling choices that have been made, and we present some preliminary results on pay dispersion. Section 4 reviews the main econometric model employed in the analysis and discusses its assumptions. Section 5 presents

\footnotetext{
${ }^{5}$ As we discuss later in the paper, the 1980 s were also a period during which managers and white collars started criticising trade unions' excessively egalitarian stands.

${ }^{6}$ The two-way fixed effects model has been estimated on Italian data in different contexts (e.g. Iranzo, Schivardi, and Tosetti [2008] and Flabbi, Macis, Moro, and Schivardi [2014]). However, none of these studies has focused on wage inequality and on its evolution over time.
} 
the main results. Finally, Section 6 contains the concluding remarks.

\section{Institutional Context and Existing Studies on Italian Wage Dispersion}

During the years considered in this study, and largely still today, Italy has been characterized by a wage setting mechanism fairly centralized at the sector-wide national level. Collective contracts are de-facto binding for all employers and all workers, irrespective of union membership. Such agreements are signed (typically every two years) by the major trade unions and employers' associations at the industry-wide level. Each contract regulates specific job titles (livelli di inquadramento) and the contractual minimum wages that is to apply for each of them. There are no opting-out clauses. That is to say, firms cannot decide to resort to firm-level contractual agreements derogating to the wage standards settled at the sectoral level. ${ }^{7}$ Regional- or firm-level agreements can only distribute top-up wage components, typically related to indicators of profitability or productivity.

Up until 1993, a cost-of-living allowance, called Scala Mobile, was also added quarterly to the bargained contractual minimum wages. This institution induced a greater proportional wage growth at the bottom of the distribution, a growth which was particularly strong before that a major reform of this system was approved through a referendum in 1985 . Those who were more disadvantaged by this indexation rule were highly qualified white-collars and skilled workers. From 1987 on, in order to further mitigate the egalitarian tendencies induced by the wage-adjustment mechanisms, the majority of the nation-wide contracts pursued a re-appraisal of the skill requirements embedded in each livello di inquadramento, widening the gaps in the contractual wages stipulated for each of these levels. ${ }^{8}$

In 1993 a major reform of collective bargaining was approved, in order to achieve the following main objectives: ${ }^{9}(i)$ impose moderation on wage growth, by coordinating wage

\footnotetext{
${ }^{7}$ Only in 2011, well beyond the time period studied in this paper, an agreement signed by trade unions and employers' organizations has attempted to widen the scope for derogation of firm-level contracts with respect to sectoral bargaining. Nevertheless, reforms in the wage setting institutions remain an actively debated policy topic in the Italian context.

${ }^{8}$ This general tendency is often highlighted by industrial relations reports of the time (e.g., CESOS [1989]).

${ }^{9}$ Casadio [2003] provides a detailed review of the content of this reform. Moreover, a detailed institutional background on the pre-1993 context is given by Erickson and Ichino [1995].
} 
increments across sectors and by setting low inflation targets; (ii) increase regional differences in wages, in order to better adapt them to the heterogeneous cost of living and labour market conditions observed in different parts of the country; ( $i i i$ ) allow firms to distribute premiums related to performance on top of the sectoral minimum, and to further negotiate some parts of the collective agreements, but not those related to compensation, at the establishment level. This reform resulted in an increase of geographical differences in top-up components of negotiated wages. However, as documented by Devicienti, Maida, and Pacelli [2008] on a sample covering around $60 \%$ of national private-sector contracts, the amount of flexibility in bargaining agreements introduced by the 1993 reform was quite limited, given that the average share of all top-up components over total wages increased from around $18 \%$ during the mid-80s, to only $22 \%$ by the end of the 1990 s.

To give a flavour of the general economic context characterizing the period under study, Figure A.4 of the Appendix shows the evolution of GDP in Italy and in the statistical area where Veneto is located. At least three phases can be identified. From the early 1980s until 1991 the economy grows, except for a short period of stagnation, which lasts until 1984. The years from 1991 to 1993 are characterized by an economic recession, which is followed by a recovery phase. From 1993 onwards, North-Eastern Italy outperforms the national economic growth level.

In Figure A.5 we compare the evolution of male and female absolute levels of employment in the Veneto private sector. To construct this figure, we have calculated the number of individuals working for at least 16 weeks in a private-sector establishment located in Veneto, and we have taken 1982 as the reference year. Women's employment level has risen more sharply than men's one. Moreover, the employment response to the 1991-1993 crisis is more pronounced for women. Considering the entire period under study, the population of workers grew by slightly less than $20 \%$ for men and by almost $50 \%$ for women. As we discuss later, this gender difference in participation is one of the main reasons that led us to study the men's and women's sample separately.

In Figure A.6, we provide an overview of the long-run evolution of real gross weekly wages, computed separately by gender from the social security records of private sector workers in 
Veneto. The average pay, which is reported in the two top panels of the figure, increased up until the early 1990s, when a phase of economic crisis begun and wage growth became persistently flat, and even declining in the case of women. Looking at the two bottom panels of the figure, we can see that inequalities, as measured by the standard deviation of log weekly wages, declined sharply until around 1983 for both gender groups. Previous research has attributed this remarkable trend to the strong compressing effects of the Scala Mobile (see, in particular, the analysis in Manacorda [2004], based on household survey data). ${ }^{10}$

As can be noticed from the bottom panels of Figure A.6, the period 1982-2001, the one on which we focus our analysis, is instead characterized by a very persistent growth in pay inequality. Other papers have studied the Italian wage inequality from the early 1980s onward, documenting a growth in pay dispersion. The main data sources that have been used are the Bank of Italy Survey on Income and Wealth (see Brandolini, Cipollone, and Sestito [2002], Manacorda [2004] and Naticchioni and Ricci [2009] among others) and the Worker History Italian Panel (WHIP), or similar administrative data containing samples of the private sector of the entire Italian territory (see, for example, Devicienti and Borgarello [2001], Cappellari [2004] and Cappellari and Leonardi [2016]).

Manacorda [2004] shows that a rise in wage dispersion occurred in Italy between 1984 and 1993. However, his analysis is limited in scope, since it focuses mainly on the effects of the Scala Mobile prior to 1984, and the evidence provided is based on repeated cross sectional household surveys, which do not allow to match workers and firms. Using the same data on a larger period of time, these results are confirmed also by Brandolini, Cipollone, and Sestito [2002]. Devicienti and Borgarello [2001] analyse a panel of administrative data covering the period 1985-1996, documenting an increase in several measures of wage inequality. However, their analysis is limited to a disaggregation of the observed trend across gender and homogeneous geographical and job-qualification groups. Cappellari [2004] studies a sample of social security records over the period 1975-1995, focusing

\footnotetext{
${ }^{10}$ Leonardi, Pellizzari, and Tabasso [2015] further investigate this issue, documenting the presence of substantial wage penalties for high skilled workers employed in firms more affected by the Scala Mobile during the 1976-1982 period.
} 
on the longitudinal persistence of men's earnings inequality. By decomposing the earnings autocovariance structure into its long-term and transitory parts, he documents an increase in the dispersion of the long-term earning component, particularly strong since the early 1990s among older cohorts of workers. ${ }^{11}$

Finally, only a few papers have specifically looked at the role played by collective bargaining institutions in the evolution of wage inequality. Such studies usually employ samples covering only a few sectors and smaller geographical areas. In particular, Dell'Aringa and Lucifora [1994] and Erickson and Ichino [1995], using a sample of metal-mechanical workers in the metropolitan area of Milan, argue that the centralized system of industrial relations plays a pivotal role in determining the Italian wage structure. Beyond their narrower coverage, the data employed in these studies have typically other limitations, which impede the estimation of a two-way fixed effect model, and of the related wage variance decomposition (e.g., an insufficient coverage of each firms' entire workforce or a limited panel dimension). Differently from the rest of the papers reviewed above, in the present analysis we will directly look at the contributions of firm wage policies, worker heterogeneity and assortative matching to the evolution of wage inequality.

\section{Data and Preliminary Evidences on Inequality}

\subsection{Database and Descriptive Statistics}

The Veneto Working Histories (VWH) database, which is studied here, contains earnings data from social security records for dependent workers of the private sector in the Veneto region. The information on pay includes maternity and sick leaves and all cash benefits, but it excludes all in-kind benefits. The database contains the population of private sector firms whose headquarters are located in Veneto, and the population of their employees. Workers of these firms are followed if they continue working in a private-sector establishment outside the Veneto region. ${ }^{12}$

\footnotetext{
${ }^{11}$ Cappellari and Leonardi [2016] focus on the relation between tenure and earning instability. They find that the introduction of temporary contracts, which occurred by the end of the 1990s, has increased the amount of earning fluctuations, particularly among younger cohorts.

${ }^{12}$ Workers are not followed if they move to the public-sector, since all public-sector workers are excluded from these archives. Moreover, for firms outside Veneto information on the entire workforce is not available.
} 
One advantage of using social security records is given by the fact that the information contained is highly accurate. Indeed, employers are obliged to report correct information on their workforce by the law. However, there are also some drawbacks, as for example the lack of important information, most notably the employees' level of education. ${ }^{13}$ Another limitation, dictated by the current data availability, is clearly the possibility to look at the evolution of wage inequality in only one region of the country. ${ }^{14}$ Nevertheless, there are several circumstances that make Veneto a particularly informative case-study. First, this region has a well-developed manufacturing sector and is fairly large, given that its population amounted to 4.5 millions in 2001 and its economy represented around $11 \%$ of the national GDP in the same year. A second, and more subtle reason why separately analysing a single region of Italy is interesting, particularly in the context of this paper, is the approval of the 1993 industrial relations reform. Indeed, this agreement introduced more flexibility at the regional level, in order to better link wages to local market conditions and inflation levels. ${ }^{15}$ Therefore, when considering the whole country, wage inequality could be over-estimated by ignoring the fact that part of its trend could be driven by a genuine adjustment of wages to the local price levels. ${ }^{16}$

The VWH database contains information on wages from 1975 until 2001, but we consider only the last two decades of the data. In particular, in the rest of the paper we study the period between 1982 and 2001, and we choose log gross daily wages, adjusted to the 2003 level, as the unit of measurement for earnings. Our choices are motivated on several grounds. The main objective of the paper is to shed light on the determinants of the

\footnotetext{
${ }^{13}$ However, under the assumption of constant individual education levels across time, the effect of this variable can be captured by the unobserved individual heterogeneity term in a panel framework.

${ }^{14}$ There are no currently available country-level longitudinal matched employer-employee data suitable for our aims. For instance, the Italian Worker History Italian Panel is a 1:90 sample of dependent workers, entailing that for many firms only a handful of workers (often just one) are observed. The only other employer-employee data source that has been analysed in the literature (i.e. the one studied by Iranzo, Schivardi, and Tosetti [2008]) allows to observe the entire workforce of each firm, but the firm sample is drawn considering only relatively large establishments.

${ }^{15}$ On this topic, Devicienti, Maida, and Pacelli [2008] document a tenuous resurrection of the Italian wage curve after 1993, mostly driven by greater regional differences in wages. This form of flexibility has been one of the main targets of the 1993 agreement, since the Italian economy has always been quite heterogeneous in terms of employment levels and costs of living, with substantial differences between Northern and Southern regions.

${ }^{16}$ Correcting for the latter is no simple task, particularly given the lack of official data on spatial price indexes.
} 
most recent growth in pay dispersion, which takes place during the last two decades of the available data. Moreover, information on days worked is reported only starting from 1982. Daily wages are a more precise measure of earnings than other available alternatives (weekly or monthly wages), since, by the law, employers have to report all weeks and months during which the employee has worked at least one day.

In order to analyse a sample of workers more homogeneous and consistent across time, we have separately considered men and women. ${ }^{17}$ Moreover, throughout the paper we mainly focus on the results of the male sample, although references to those obtained among women are often included for comparison purposes. We have also taken a number of steps that are relatively standard in the literature using similar data. First, for each employee with multiple jobs during the same year, we have selected the most representative spell in terms of months, weeks and days worked, resorting to total earnings to break the few remaining ties. Second, we have excluded from the sample all spells shorter than approximately four months (16 weeks) and, finally, we have trimmed wages at the 1st and 99th percentiles (calculated over a six-year period).

We have divided the 1982-2001 years of data into five, partially overlapping, six-years panels. In each period, we have separately estimated the two-way fixed effect model of Abowd, Kramarz, and Margolis [1999] over the respective largest connected set. ${ }^{18}$ Finally, all results are computed over firms of Veneto only, but we have included also employment spells outside this region in the estimation sample of the two-way fixed effect model. The rationale of these choices is discussed in the section providing the details of our econometric method.

Tables 1 and 2 contain descriptive statistics for each of the five panels that we have constructed, computed separately by gender. ${ }^{19}$ As can be noticed, the (non-weighted) average

\footnotetext{
${ }^{17}$ As shown by Figure A.5, the observed employment dynamics are indeed quite different among men and women.

${ }^{18}$ This is a set of workers and firms connected by employees' mobility. This restriction implies the loss of an extremely small proportion of observations, and is usually applied to simplify estimations. See Abowd, Creecy, and Kramarz [2002] for a discussion.

${ }^{19}$ In reading these figures, notice that the secondary sector is over-represented, given that public sector workers are excluded from the social security archives. This pattern is reflected in the occupational composition of the sample, where the majority of individuals are blue-collars.
} 
firms' size, as measured by the number of employees continuously working for at least six months in a year, tends to be quite small and it is decreasing over time. This tendency, considered together with rising employment levels and secondary sector jobs, shows that the overall economic growth experienced by Veneto during the years under study has been closely linked to a growth in the number of small-sized manufacturing oriented establishments. The distribution of firm size is highly dispersed and positively skewed, since also very small companies are included in our database. This last feature is worth noticing, given that small firms are often not observed in traditional samples (see footnote 14), despite being an important component of the Italian economy. ${ }^{20}$

Among other tendencies emerging from the tables, notice that the average age increases for women in later years of the sample, despite being quite stable across men. This outcome can in part be attributed to the higher education levels reached by younger cohorts of women, a tendency determining a later entrance in the labour market. Moreover, the average growth in women's age is also linked to the greater labour market attachment experienced by younger cohorts of female workers at later stages of their careers. There are other substantial gender differences in the sample composition. In particular, females are under-represented in managerial occupations and they are much more likely to work par-time. Part-time contracts have been introduced in the Italian legislation only since 1985, and this explains why they tend to be quite rare in the earlier years of the data. The over-representation of women in this category of workers poses challenges on the comparability of results obtained for men and women, and it is another important reason for keeping our analysis of pay dispersion separated by gender.

Finally, notice that real wages are quite flat during the overall period considered, while their dispersion, as measured by the standard deviation, steadily increases both among women and men. In the next paragraph, we are going to present a more accurate description of this trend.

\footnotetext{
${ }^{20}$ According to the figures of the Italian Statistical Office (ISTAT - ASIA 2011) plants with less than 10 workers represent around $95 \%$ of the firms' population at the national level, and they employ around $46 \%$ of the private-sector workforce.
} 
Table 1: Male Sample Summary Statistics (Mean and St. Dev.)

\begin{tabular}{|c|c|c|c|c|c|}
\hline Period & $1982-1987$ & 1984-1989 & 1988-1993 & $1992-1997$ & 1996-2001 \\
\hline $\begin{array}{l}\text { Log daily wages } \\
\text { St. Dev. }\end{array}$ & $\begin{array}{l}4.782 \\
0.287\end{array}$ & $\begin{array}{l}4.801 \\
0.303 \\
\end{array}$ & $\begin{array}{l}4.855 \\
0.337 \\
\end{array}$ & $\begin{array}{l}4.866 \\
0.350 \\
\end{array}$ & $\begin{array}{l}4.874 \\
0.362 \\
\end{array}$ \\
\hline $\begin{array}{l}\text { Age } \\
\text { St. Dev. }\end{array}$ & $\begin{array}{l}36.76 \\
11.07 \\
\end{array}$ & $\begin{array}{l}36.37 \\
11.04\end{array}$ & $\begin{array}{l}35.94 \\
10.91\end{array}$ & $\begin{array}{l}35.83 \\
10.40\end{array}$ & $\begin{array}{c}35.81 \\
9.85\end{array}$ \\
\hline $\begin{array}{l}\text { Firms' workers } \\
\text { St. Dev. }\end{array}$ & $\begin{array}{l}7.884 \\
55.30 \\
\end{array}$ & $\begin{array}{l}7.392 \\
48.77 \\
\end{array}$ & $\begin{array}{l}7.031 \\
39.05 \\
\end{array}$ & $\begin{array}{l}7.500 \\
52.09 \\
\end{array}$ & $\begin{array}{c}7.419 \\
49.023 \\
\end{array}$ \\
\hline $\begin{array}{l}\text { Tenure } \\
\text { St. Dev. }\end{array}$ & $\begin{array}{l}5.072 \\
3.631\end{array}$ & $\begin{array}{l}5.552 \\
4.325\end{array}$ & $\begin{array}{l}6.013 \\
5.494\end{array}$ & $\begin{array}{l}6.451 \\
6.252\end{array}$ & $\begin{array}{l}6.479 \\
6.823\end{array}$ \\
\hline $\begin{array}{l}\text { Proportion } \\
\text { Part Time }\end{array}$ & 0.002 & 0.004 & 0.007 & 0.011 & 0.016 \\
\hline $\begin{array}{l}\text { Proportion } \\
\text { Apprentice }\end{array}$ & 0.016 & 0.020 & 0.025 & 0.025 & 0.035 \\
\hline $\begin{array}{l}\text { Proportion } \\
\text { Blue Collar }\end{array}$ & 0.730 & 0.729 & 0.723 & 0.723 & 0.708 \\
\hline $\begin{array}{l}\text { Proportion } \\
\text { White Collar }\end{array}$ & 0.247 & 0.243 & 0.242 & 0.244 & 0.250 \\
\hline $\begin{array}{l}\text { Proportion } \\
\text { Manager }\end{array}$ & 0.007 & 0.007 & 0.008 & 0.007 & 0.007 \\
\hline $\begin{array}{l}\text { Proportion } \\
\text { Primary Sect. }\end{array}$ & 0.043 & 0.045 & 0.045 & 0.044 & 0.042 \\
\hline $\begin{array}{l}\text { Proportion } \\
\text { Secondary Sect. }\end{array}$ & 0.626 & 0.631 & 0.648 & 0.651 & 0.663 \\
\hline $\begin{array}{l}\text { Proportion } \\
\text { Tertiary Sect. }\end{array}$ & 0.331 & 0.324 & 0.307 & 0.305 & 0.295 \\
\hline Total Workers & 698,378 & 724,448 & 753,753 & 777,019 & 845,984 \\
\hline Total Firms & 64,972 & 72,605 & 80,159 & 80,572 & 85,104 \\
\hline
\end{tabular}

The sample is composed of firms located in Veneto belonging to the largest connected set.

Part-time contracts have been introduced only since 1985. Tenure is censored at 1975. 
Table 2: Female Sample Summary Statistics (Mean and St. Dev.)

\begin{tabular}{|c|c|c|c|c|c|}
\hline Period & 1982-1986 & 1984-1989 & 1988-1993 & 1992-1997 & 1996-2001 \\
\hline $\begin{array}{l}\text { Log daily wages } \\
\text { St. Dev. }\end{array}$ & $\begin{array}{l}4.547 \\
0.277\end{array}$ & $\begin{array}{l}4.555 \\
0.276 \\
\end{array}$ & $\begin{array}{l}4.585 \\
0.317 \\
\end{array}$ & $\begin{array}{l}4.574 \\
0.345 \\
\end{array}$ & $\begin{array}{l}4.549 \\
0.372 \\
\end{array}$ \\
\hline $\begin{array}{l}\text { Age } \\
\text { St. Dev. }\end{array}$ & $\begin{array}{c}31.47 \\
9.86 \\
\end{array}$ & $\begin{array}{c}31.25 \\
9.68\end{array}$ & $\begin{array}{c}31.31 \\
9.36 \\
\end{array}$ & $\begin{array}{c}32.37 \\
9.26\end{array}$ & $\begin{array}{c}33.45 \\
9.30\end{array}$ \\
\hline $\begin{array}{l}\text { Firms' Workers } \\
\text { St. Dev. }\end{array}$ & $\begin{array}{l}9.427 \\
50.56 \\
\end{array}$ & $\begin{array}{l}8.275 \\
43.99 \\
\end{array}$ & $\begin{array}{l}7.556 \\
44.78 \\
\end{array}$ & $\begin{array}{l}7.991 \\
52.64 \\
\end{array}$ & $\begin{array}{l}7.375 \\
43.09 \\
\end{array}$ \\
\hline $\begin{array}{l}\text { Tenure } \\
\text { St. Dev. }\end{array}$ & $\begin{array}{l}4.497 \\
3.414\end{array}$ & $\begin{array}{l}4.837 \\
4.003\end{array}$ & $\begin{array}{l}5.082 \\
4.925\end{array}$ & $\begin{array}{l}5.603 \\
5.642\end{array}$ & $\begin{array}{l}5.749 \\
6.284\end{array}$ \\
\hline $\begin{array}{l}\text { Proportion } \\
\text { Part Time }\end{array}$ & 0.022 & 0.046 & 0.097 & 0.138 & 0.195 \\
\hline $\begin{array}{l}\text { Proportion } \\
\text { Apprentice }\end{array}$ & 0.024 & 0.033 & 0.036 & 0.032 & 0.052 \\
\hline $\begin{array}{l}\text { Proportion } \\
\text { Blue Collar }\end{array}$ & 0.621 & 0.616 & 0.582 & 0.593 & 0.546 \\
\hline $\begin{array}{l}\text { Proportion } \\
\text { White Collar }\end{array}$ & 0.349 & 0.346 & 0.360 & 0.373 & 0.399 \\
\hline $\begin{array}{l}\text { Proportion } \\
\text { Manager }\end{array}$ & 0.001 & 0.000 & 0.000 & 0.000 & 0.000 \\
\hline $\begin{array}{l}\text { Proportion } \\
\text { Primary Sect. }\end{array}$ & 0.043 & 0.045 & 0.047 & 0.048 & 0.050 \\
\hline $\begin{array}{l}\text { Proportion } \\
\text { Secondary Sect. }\end{array}$ & 0.511 & 0.517 & 0.514 & 0.499 & 0.492 \\
\hline $\begin{array}{l}\text { Proportion } \\
\text { Tertiary Sect. }\end{array}$ & 0.446 & 0.437 & 0.439 & 0.453 & 0.458 \\
\hline Total Workers & 406,988 & 442,871 & 493,208 & 518,292 & 603,106 \\
\hline Total Firms & 42,600 & 52,804 & 67,263 & 67,476 & 78,797 \\
\hline
\end{tabular}

The sample is composed of firms located in Veneto belonging to the largest connected set.

Part-time contracts have been introduced only since 1985. Tenure is censored at 1975. 


\subsection{Preliminary Evidences on Inequality}

Figure 1 describes the evolution of log daily wages at the 10th, 50th and 90th percentiles of the gender- and year-specific earning distribution. It can be easily noticed that the 90th-10th, 50th-10th and 90th-50th wage percentile ratios have all increased. Another striking evidence is the very slow, and even negative growth of wages. In particular, men's earnings at the bottom of the distribution have remained stable over the whole period, median wages have risen by less than $2 \%$ and the 90 th percentile of the pay distribution has risen by almost $6 \%$ in real terms, but it has been stagnating during most of the 1990 s. Instead, women's percentiles ratio have started to widen later than men's ones. Notice that, from the beginning of the 1990s female wages at the bottom of the distribution have declined by around $4 \%$, while they have risen by almost the same amount at the 90 th percentile, following a similar pattern to men's top earnings. The declining dynamic of female wages at the bottom of the distribution is partly explained by the introduction of part-time contracts, which have played an important role in increasing female participation to the labour market.

In the left panels of Figures 2 and 3 we test the predictive performance of a series of log-linear conditional wage models. To construct these figures, we have run year-by-year OLS regressions on the workers of firms located in Veneto, using different sets of controls. In each figure, the highest line of the left-panel graph represents the unconditional log wage variance. The other lines represent the root mean squared error (RMSE) of yearspecific regression models. In each model, we have used the same set of base-line covariates, namely: a quadratic in age, occupation dummies, tenure dummies, log of firm size (number of employees), around thirty sector fixed effects, national industry-wide collective contract fixed effects, a set of interactions (age with occupation and age with tenure). In addition to these covariates, each regression model is fully saturated for one of the following categories: (1) job titles (livelli di inquadramento), (2) firms or (3) both. ${ }^{21}$

\footnotetext{
${ }^{21}$ Notice that national industry-wide collective contract fixed effects are not collinear with job title fixed effects, since the latter are specific occupations (usually between five and ten) defined by the former. Instead, firm fixed effects are collinear with sector fixed effects and, typically at least, also with industrywide contracts fixed effects. The procedure adopted in constructing job title and collective contract fixed effects will be discussed in more detail in Section 5.3.
} 
The RMSE provides a measure of the performance of each model in explaining total wage variation. In general, the trend in residual wage variance is fairly flat, while the total pay variance, both in the case of men and women, shows a clear increasing pattern. This is a preliminary evidence that workforce composition and returns to its characteristics do a good job in explaining the rise in wage dispersion over time, and are becoming increasingly relevant over time. Obviously, none of the estimated models reported here does control for constant unobserved individual characteristics. Nevertheless we can see that a fairly small proportion of the unconditional wage variation remains unexplained, especially when we estimate a model fully saturated for job titles and firms. Firm fixed effect explain a greater proportion of wage variation than job title fixed effects. However, when focusing on the evolution of the RMSE across time, this same pattern does not hold.

In order to better compare the evolution in the relative performance of each of the three regression models, in the right panels of Figures 2 and 3 we normalize each year-specific RMSE to the 1982 level of the corresponding model. ${ }^{22}$ A clear pattern emerges both in the male and female samples. Over time, the explanatory power of fixed effects for job titles gains importance with respect to the models where firm effects are controlled for. Since inquadramento levels are defined by sector-wide collective agreement, and a particular minimum wage is set for each of these occupational positions, we interpret the right panels of Figures 2 and 3 as a preliminary evidence of the importance of collective bargaining in shaping the evolution of the pay distribution. In Section 5.3, employing a more informative regression framework, we analyse this point in more detail.

\footnotetext{
${ }^{22}$ In interpreting the graph, notice that the absolute predictive performance of a model has to be evaluated with respect to the unconditional wage variance. The left panel of Figures 2 and 3 is useful in order to compare the relative predictive performance of a model with respect to the others, but not the absolute one, which indeed tends to grow over time.
} 


\section{Figure 1: Evolution of Log Daily Wages at Various Percentiles}
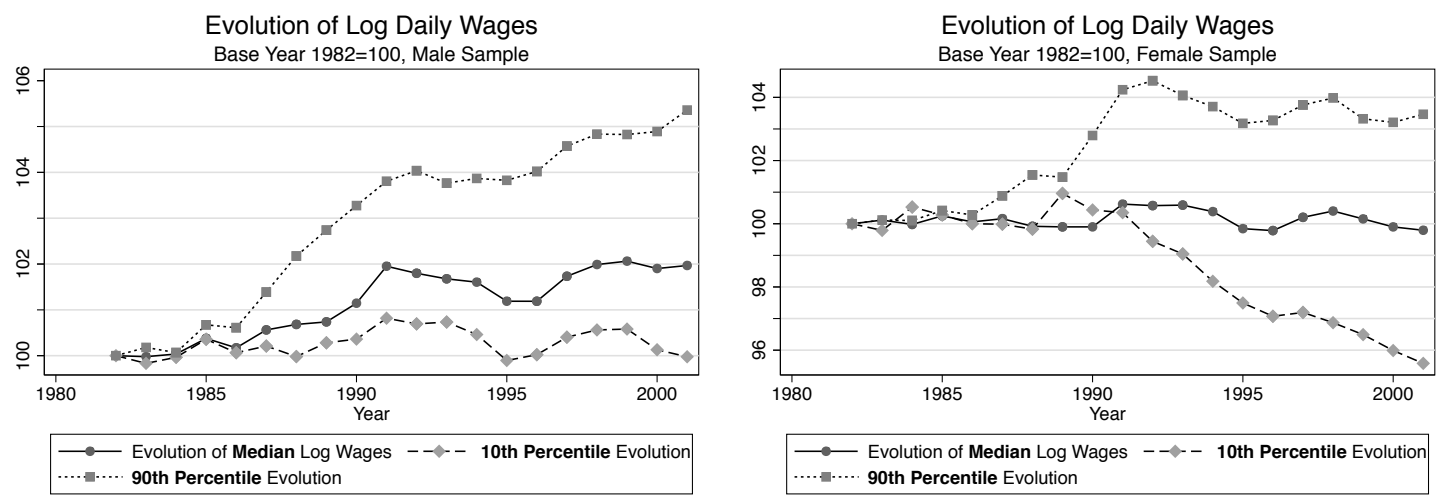

Figure 2: Wage St. Dev. and RMSE from Alternative Wage Models Male Sample, Year-by-Year Regressions
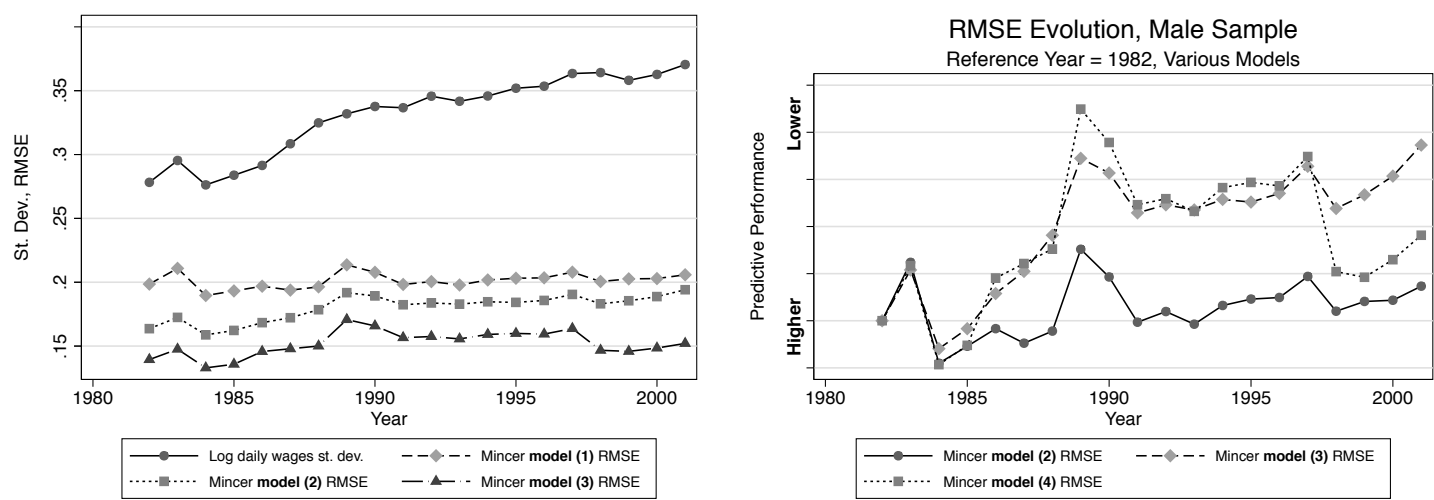

Baseline controls: age (quadratic), tenure dummies, four qualification dummies, log of employees number, sector fixed effects, national industry-wide collective contract fixed effects.

Model (1): job title (livello di inquadramento) fixed effects.

Model (2): firm fixed effects.

Model (3): fully saturated fixed effects for job titles and firms.

Note: national collective contracts vary within and across sectors, and might be not homogeneous across years. Inquadramento levels are occupational positions determined by each national collective contract, and are not homogeneous across years. 
Figure 3: Wage St. Dev. and RMSE from Alternative Wage Models Female Sample, Year-by-Year Regressions
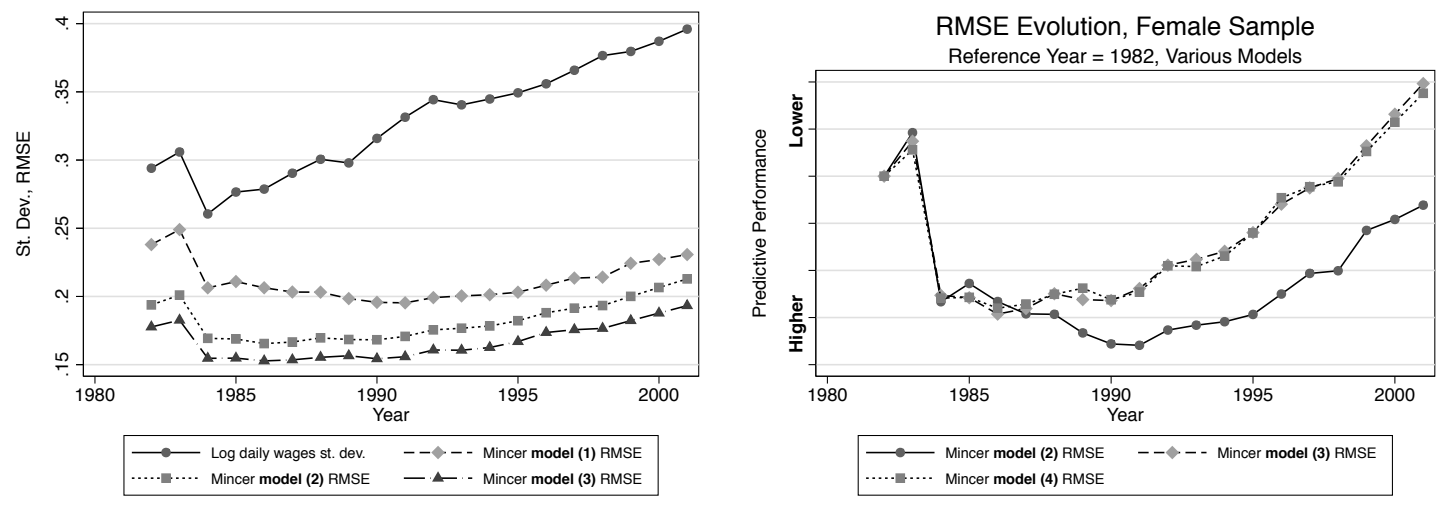

Baseline controls: age (quadratic), tenure dummies, four qualification dummies, log of employees number, sector fixed effects, national industry-wide collective contract fixed effects.

Model (1): job title (livello di inquadramento) fixed effects.

Model (2): firm fixed effects.

Model (3): fully saturated fixed effects for job titles and firms.

Note: national collective contracts vary within and across sectors, and might be not homogeneous across years. Inquadramento levels are occupational positions determined by each national collective contract, and are not homogeneous across years. 


\section{Econometric Methodology}

The contributions of firm-specific, time-constant and time-varying components of wages to raising inequality are identified relying on the higher-dimensional linear panel model of Abowd, Kramarz, and Margolis [1999] (we will alternatively refer to this method as twoway fixed effects model and AKM regression). Moreover, in order to make inter-temporal comparisons, we adopt the same strategy of Card, Heining, and Kline [2013], dividing the years under study into different sub-periods. In this section, we briefly review the chosen econometric methodology, we explain the required assumptions, and we discuss the interpretation of the model.

Let $i$ index a specific worker, $t$ the time period, and $j=\iota(i, t)$ the firm in which $i$ is working at $t$. Moreover, let $y_{i}$ represent a $T \times 1$ vector of log wages, $x_{i}$ a $T \times P$ matrix of time- and firm-varying individual characteristics. Then, the two-way fixed effects model can be specified as follows

$$
y_{i t}=x_{i t} \beta+\phi_{j}+\eta_{i}+e_{i t}
$$

where $y_{i t}$ and $x_{i t}$ are elements of $y_{i}$ and $x_{i}, \beta$ is a $P \times 1$ vector of parameters, while $\phi_{j}$ and $\eta_{i}$ are respectively firm-constant and time-constant components of individual wages, which are allowed to be arbitrarily correlated with any of the characteristics in $x_{i}$, and which could be not perfectly observable. Notice that we will often refer to $\eta_{i}$ with the term unobserved individual heterogeneity, and to $\phi_{j}$ with firm wage premium or firm wage policy.

Instead, $e_{i t}$ is the error term, which we assume to have an expected value equal to zero in all periods. Moreover, it is an idiosyncratic shock, which is not allowed to be correlated with any of the elements in $x_{i}, \phi_{j}$ and $\eta_{i}$. This assumption, which we define as strict exogeneity, can be stated formally as

$$
E\left[e_{i t} \mid x_{i s}, \phi_{j=\iota(i, s)}, \eta_{i}\right]=0 \quad \forall s, t
$$

Notice that the above assumption rules out any pattern of endogenous mobility of workers between firms. Any realization of $\iota(i, s)=j$ should be uncorrelated with $e_{i, t}$, so that, for example, negative idiosyncratic shocks in wages should not lead to mobility towards 
a certain type of firms. However, any correlation between $\iota($.$) and \eta_{i}$ or $\phi_{j}$ is possible, so that workers of a given type can move toward firms with certain wage policies and vice-versa. If strict exogeneity holds, the model can be consistently estimated by OLS, via inclusion of dummies for individuals' and firms' effects.

The hypothesis of exogenous worker mobility across firms, conditional on individual observable and time-constant unobservable characteristics, has been criticised, e.g. by Eeckhout and Kircher [2011] who point out that many search and matching models of the labour market are inconsistent with the additive linearity of the AKM approach. Card, Heining, and Kline [2013] develop several tests to support the validity of the strict exogeneity assumption. These tests have been conducted on German data (Card, Heining, and Kline [2013]) and on Portuguese data (Card, Cardoso, and Kline [2016]), both papers concluding that the AKM model provides an accurate approximation to wage determination in these countries. Flabbi, Macis, Moro, and Schivardi [2014] apply similar tests on Italian Social Security earnings data, covering a sample of firms above 50 employees over a period similar to the one analysed here, and do not report any evidence of AKM misspecification.

Table 3 reports, for each of the AKM model estimation samples, the proportion of individuals changing employer (the so-called movers) over the total number of individuals ever working at the firm. ${ }^{23}$ All of the statistics computed for this variable are weighted by the number of distinct firm's employees included in the sample. Over the two decades analysed, workers' mobility tends to grow. ${ }^{24}$ Despite this trend, mobility of workers is fairly strong also during the 1980s. Indeed, during the period 1982-1987, on average $45 \%$ of the workforce at a given firm was hired also by at least one of the other employers included in the estimation sample. The same percentage was of almost $60 \%$ during the latest period analysed (1996-2001). Even among employers with the most stable workforce, those at the

\footnotetext{
${ }^{23}$ Table 3 is computed on male workers only. Results obtained on the female sample are reported in Table A.1.

${ }^{24}$ This outcome can be interpreted as evidence of greater job instability in the most recent years. This tendency has been triggered by several reforms, such as more flexible employment protection legislations and the liberalization of the hiring process. Moreover, also market forces, such increased volatility, international competitiveness and outsourcing, may have played an important role.
} 
10th percentile of the mobility proportion distribution, the percentage of job-movers was 11\% during 1982-1987. The (weighted) median number of movers per firm ranges between 20 in 1982-1987 and 26 during the period 1996-2001. Overall, the amount of mobility observable in the data, despite not being uniform across periods, seems to be large enough to provide a good estimate of the firm wage policies.

Our baseline control variables included in the AKM model are a quadratic for age, a dummy for part-time workers, ${ }^{25}$ three dummies for occupation, the log of the number of employees, six dummies for the first five years of tenure, ${ }^{26}$ and a full set of time fixed effects. Moreover, we add interactions between age and occupation dummies, age and tenure dummies, and firm size and time dummies. As a robustness check, we have excluded part-timers and apprentices from the computations, finding qualitatively similar results. Moreover, we have estimated the model by including sector-specific time effects, but again we did not find major differences in the results.

The estimated individual fixed effects measure the individual earning capacity that is constant over time, and largely portable as the individual moves to other firms during his/her labour market career. Education, skills, professional networks and other personal factors, which are constant or change slowly over time, all contribute to this component, to the extent that they are rewarded equally across employers. Instead, the estimated firm fixed effect measure how much differences in wages paid by observationally similar employers matter, keeping constant employee quality and other observable characteristics. Unlike a simple average of the workers' wages in the firm, $\phi_{j}$ can be interpreted as a firm-specific wage policy because the AKM model controls for worker observed and unobserved heterogeneity, and hence accounts for the potential non-random sorting of workers to firms. ${ }^{27}$

\footnotetext{
${ }^{25}$ Part-time contracts have been introduced in the Italian legislation only in 1985. Prior to that date, part-time was informal, and mostly horizontal in nature.

${ }^{26}$ This discrete specification for the variable tenure is motivated by the fact that the information on tenure is censored up to 1975 .

${ }^{27}$ Apart from the above mentioned restriction on the endogenous mobility of workers, one limitation of this model is given by the fact that firms wage premiums cannot be interpreted as indexes of firms productivity or efficiency. Indeed, as shown by Eeckhout and Kircher [2011], using wage data alone the contribution to productivity of a skilled worker cannot be disentangled from the contribution of the firm technology, since the two are simultaneously determined, and, most importantly, not monotonically related. Nevertheless, since the focus of this analysis is on the determinants of wage dispersion rather than workers' productivity, the estimated firms wage policies remain an interesting parameter.
} 
Notice that, as the AKM dependent variable is log wages, $\phi_{j}$ represent a proportional firm-specific wage premium paid by firm $j$ to all its employees.

There are several reasons why similar firms may adopt differentiated wage policies. As highlighted by a vast stream of literature, firms might offer wages higher than the equilibrium level as part of an exchange of gifts with their employees (as in the efficiency wage theory set forth by Akerlof [1982]). Moreover, similar firms might adopt a so-called wage posting behaviour, offering higher wages in order to reduce the cost of vacancies (e.g. Burdett and Mortensen [1998]). Finally, firms might differ in the degree of rent-sharing, a phenomenon which has been found to be small, but significant in magnitude, in the labour market analysed here. Indeed, using the years from 1995 to 2001 of the database studied here, Card, Devicienti, and Maida [2014] find an elasticity of wages with respect to profits of around $5 \%$.

Roughly speaking, firms' effects in the AKM regression are identified as the average wage shock experienced at a given establishment by employees who changed employer during the period considered. Each firm effect is computed with respect to an arbitrary reference category and, as shown by Abowd, Creecy, and Kramarz [2002], it is identified only by workers who changed at least one employer within a given mobility group. ${ }^{28}$ Therefore, in our analysis we have considered only the largest connected set of establishments, which usually contains, depending on the years considered, more than $95 \%$ of the sample observations. Moreover, since the estimates of firms wage premiums could be biased whenever the number of mobility episodes is low and the entire workforce is not observable, we will compute and report the main results only for firms located in Veneto. ${ }^{29}$

Given the linearity of our panel model, and under the assumption of strict exogeneity, the

\footnotetext{
${ }^{28} \mathrm{By}$ mobility group, or connected set, we intend the group containing all workers who ever worked for any of the firms in the group, and all the firms at which any of the workers in the group were ever employed.

${ }^{29}$ Firms excluded from the decomposition are nevertheless included in the regression, since otherwise we would have a loss in efficiency. The choice of not reporting results for firms outside Veneto is motivated by the fact that for such establishments we do not have information on the entire workforce. See Andrews, Gill, Schank, and Upward [2008] for a discussion of the effects of limited mobility bias in the estimates of firms-wage premiums.
} 
total variance of log wages can be decomposed as follows

$$
\begin{aligned}
\operatorname{Var}\left(y_{i t}\right) & =\operatorname{Var}\left(\phi_{j=\iota(i, t)}\right)+\operatorname{Var}\left(\eta_{i}\right)+\operatorname{Var}\left(x_{i t} \beta\right)+\operatorname{Var}\left(\epsilon_{i t}\right)+ \\
& +2 \operatorname{Cov}\left(\phi_{j=\iota(i, t)}, \eta_{i}\right)+2 \operatorname{Cov}\left(\phi_{j=\iota(i, t)}, x_{i t} \beta\right)+2 \operatorname{Cov}\left(\eta_{i}, x_{i t} \beta\right)
\end{aligned}
$$

Each component in the right-hand side of the above equation can be recovered from the estimated parameters of our regression model. It follows that we can measure which are, among firm-specific, time-constant and time-varying factors, the main drivers of wage dispersion, and which forces lessen their magnitude over time. Notice that, with the exception of the error term, the effect of each component on the total variance is mediated by the covariance terms. Of particular interest are the covariances associated to firms' pay premiums, since they measure positive or negative sorting of individuals with given characteristics into types of firms adopting specific wage policies. Instead, the term $\operatorname{Cov}\left(\eta_{i}, x_{i t} \beta\right)$ measures whether workers with higher wage components related to their time-varying characteristics also tend to exhibit higher (positive covariance) or lower (negative covariance) components related to their time constant unobserved heterogeneity.

In practice it is often difficult to understand which human capital factors are absorbed by unobserved heterogeneity, and what drives the sorting between time-varying and timeconstant characteristics of workers. To some extent $\operatorname{Cov}\left(\eta_{i}, x_{i t} \beta\right)$ is determined by how well given workers' skills are measured by the time-varying characteristics included in the regression. ${ }^{30}$ Given these difficulties, in presenting our results we will most often rely on the following, more parsimonious decomposition

$$
\begin{aligned}
\operatorname{Var}\left(y_{i t}\right) & =\operatorname{Var}\left(\phi_{j=\iota(i, t)}\right)+\operatorname{Var}\left(\eta_{i}+x_{i t} \beta\right)+\operatorname{Var}\left(\epsilon_{i t}\right)+ \\
& +2\left[\operatorname{Cov}\left(\phi_{j=\iota(i, t)}, \eta_{i}\right)+\operatorname{Cov}\left(\phi_{j=\iota(i, t)}, x_{i t} \beta\right)\right]
\end{aligned}
$$

\footnotetext{
${ }^{30}$ For example, $\eta_{i}$ could capture the effect of professional networks' quality. However, by including in $x_{i t}$ a control for tenure interacted with age and occupation, we might provide a good proxy of networks' quality for experienced, highly qualified workers, and a bad proxy for inexperienced, less qualified workers. Then, we could have a situation in which $\eta_{i}$ is lower for individuals with the best networks, simply because for these workers the quality of networks is captured by a time-varying characteristic. This will of course depend on how the wage-networks relation operates, and on how networks' quality is distributed in the population.
} 
This decomposition is equivalent to the previous one, with the only exception that in equation (2) the term $\operatorname{Var}\left(\eta_{i}+x_{i t} \beta\right)$ captures the joint effect of workers' time-constant and time-varying characteristics. We will often refer to $\left(\eta_{i}+x_{i t} \beta\right)$ with the term workers' wage premiums, in order to distinguish this source of wage variability, which is individualspecific, from firms' pay premiums. Given the already mentioned difficulties in interpreting differences between returns to time-constant and time-varying workers' characteristics, we believe that $\operatorname{Var}\left(\eta_{i}+x_{i t} \beta\right)$ can be considered a more comprehensive and more precise measure of dispersion in employees' overall earning abilities. 
Table 3: Proportion of Job Mobility Episodes per Firm, Male Sample

\begin{tabular}{l|c|c|c|c} 
Period & Mean & $\begin{array}{c}\text { 10th } \\
\text { Percentile }\end{array}$ & $\begin{array}{c}\text { 50th } \\
\text { Percentile }\end{array}$ & $\begin{array}{c}\text { 90th } \\
\text { Percentile }\end{array}$ \\
\hline 1982-1987 & 0.450 & 0.110 & 0.400 & 0.889 \\
$1984-1989$ & 0.496 & 0.137 & 0.474 & 0.909 \\
$1988-1993$ & 0.571 & 0.214 & 0.556 & 0.952 \\
$1992-1997$ & 0.581 & 0.234 & 0.562 & 0.951 \\
$1996-2001$ & 0.595 & 0.254 & 0.588 & 0.942 \\
\hline \hline
\end{tabular}

The statistics refer to the proportion of individuals experiencing job-to-job transitions over the total number of individuals ever working at the firm during the 6-year period. Each statistic is weighted for the number of individuals ever employed by the firm. Only firms of Veneto belonging to the largest connected set are considered. 


\section{Main Results}

This section discusses the main results of the paper. They are based on the AKM regression model described in the previous section, and on the associated variance decomposition technique. We have estimated the two-way fixed effect model focusing on the evolution of its parameters over time, and the results of this analysis are presented in the next paragraph. Section 5.2 discusses some institutional features that have most likely influenced the evolution of the wage structure in the Italian case, and compares the results of the AKM regressions with those obtained on German data by Card, Heining, and Kline [2013]. Finally, in Section 5.3 we propose an empirical strategy in order to assess whether the variability and evolution of unconditional wages and worker's pay premiums, as defined by equation (2), have been influenced by the growth of between-job titles minimum wages differences.

\subsection{Variance Decomposition from the AKM Regressions}

As already mentioned, we have calculated the variance decomposition of equation (1) on five, partially overlapping, six-years gender-specific panels. Here, we discuss the results obtained in the male sample, as all of the analysis that follows this section is conducted considering male workers only. ${ }^{31}$ Results for female workers are reported in Section A.2. In each panel, we have computed two-way fixed effects regressions controlling for human capital and aggregate shocks in wages. The coefficients associated to the regressors included in $x_{i t}$ were all significant and had the expected sign. ${ }^{32}$ For each period, Table 4 reports the results from the wage variance decomposition based on equation (1).

During the overall period considered, the total wage variance, as computed on each sixyears panels, has increased from 0.83 to 0.131 , growing by almost $45 \% .{ }^{33}$ When looking at

\footnotetext{
${ }^{31}$ Even if some similarities in the observed patterns emerge, substantial gender differences in participation rates and in the use of part-time contracts makes the results obtained for women seldom comparable to the ones obtained in the male sample. Thus, a more careful assessment of the evolution of the female wage distribution is out of the scope of the present analysis.

${ }^{32}$ In particular, in all periods returns to age are positive and slightly marginally decreasing. Moreover, there are wage losses during the first years of tenure and wage gains for white-collars. See Section 3.1 for a complete list of the regressors. Notice that the MSE for each estimation of this model is reported in Table 4. The overall $\mathrm{R}$ squared ranges between 0.69 and 0.77 in the male sample.

${ }^{33}$ To put our results in perspective, notice that Card, Heining, and Kline [2013] find that the total variance of male wages had risen in West Germany from 0.136 during 1985-1991, to 0.187 during 1996-
} 
the behaviour of the various components of pay, a few noticeable features emerge. First, in each period, the largest contribution to the total variance derives from the joint effect of worker heterogeneity, both observed and unobserved. In general, the variance of $\eta_{i}$ dominates the variance of $x_{i t} \beta$. However, as mentioned in the previous section, disentangling the relative contributions of the two worker components is tricky from an empirical point of view. Indeed, the covariance of the two components shows quite an erratic behaviour, with high negative values in the sub-periods where the variance of $x_{i t} \beta$ is relatively larger. This is the main reason why, in the rest of the paper, we will focus on the more parsimonious decomposition of equation (2).

A second feature of the results is that the component related to firms' wage premiums provides a smaller contribution to overall wage dispersion than worker heterogeneity, and this is true even if we compare it solely to worker's unobserved heterogeneity. Importantly, firm wage premiums are more relevant in the first period of the sample (1982-1987), but lose importance thereafter. Finally, the estimated correlation between the firm wage effect and the worker's heterogeneity, considering jointly both the observed and unobserved components, tends to be negative in the earliest years, but it is clearly increasing over time and positive during the last years considered. Hence, there is a significant tendency towards positive sorting of firms' wage premiums with workers' overall human capital.

To show these trends more clearly, in Table 5 we have reported the decomposition of equation (2), computed in the first and in the last panel only. This less detailed decomposition has a straightforward interpretation. The wage component related to the workers' timevarying observable characteristics and the component deriving from their time-constant unobservable skills are here jointly considered. Firms' pay premiums, and the way in which they are sorted with workers attributes, form the other two main components of total wage dispersion. When separately considering the period 1982-1987 and the period 1996-2001, the most important determinant of total wage dispersion is the variance of the

2002 , which translates into a $31.5 \%$ increase. Instead, in our data we find that the male wage variance has increased from 0.092 during 1984-1989 to 0.131 during 1996-2001, which translates into a $35 \%$ increase. Finally, notice that Iranzo, Schivardi, and Tosetti [2008], analysing a sample of large Italian firms during the entire period 1981-1997, find the total male wage variance in the largest connected set to be 0.11 . 
term $\left(\eta_{i}+x_{i t} \beta\right)$. Indeed, this component constitutes between two thirds and three fourth of the total pay variance in the male sample.

In the lower part of Table 5 we analyse the evolution of earning dispersion from the earliest to the latest panel. For each component of the total variance, we have computed the difference across samples, the percentage change, and the contribution of this change as a percentage of the change in total wage variance. Between these two periods, total wage variance has risen by almost $45 \%$ among men. More than $52 \%$ of this growth is driven by higher dispersion in our comprehensive measure of workers' skills. Increasing assortative matching between highly paid workers and better paying firms is another contributing factor to the overall growth in wage dispersion. Despite the correlation between the individual component of wages and $\phi_{j}$ is relatively small in all periods, it switches from negative to positive between the initial and final sub-periods of our data, contributing to another $64 \%$ of the total change. Finally, the dispersion in firms' wage premiums declines between the first and the last panel, providing a negative contribution of about $15 \%$ to the overall growth in wage dispersion.

The results presented so far can be summarized as follows. More than two thirds of the variation of Italian wages is determined by the combined effect of workers' time-varying and time-constant individual characteristics. ${ }^{34}$ Earning dispersion has increased during the overall period considered, and the worker-specific component of wages has been an important factor driving this trend. Instead, we find that the importance of the dispersion in firm-specific wage policies has declined over time. In the rest of the paper we interpret the emergence of these results in light of the specific features of the Italian system of Industrial relations.

According to our estimates, a rising (positive) assortative matching between firms' pay premiums and the human capital of their workforce has also represented a significant contributing factor to the overall growth in wage inequality. In particular, while firms paying

\footnotetext{
${ }^{34}$ Iranzo, Schivardi, and Tosetti [2008] apply AKM regression models over similar data (albeit their sample covers only firms with 50+ employees) but with a focus on the entire period 1981-1997 (i.e., without focusing on the temporal evolution of wage inequality, and its components), and also find that roughly two thirds of the total wage variance is explained by worker-specific pay premiums.
} 
lower wage premiums were the ones hiring on average more skilled workers up until the mid-80s, this negative sorting has reversed since then. The reasons for this phenomenon are likely to be complex, and cannot be fully explained within the scope of the present paper. It is, however, tempting to relate growing assortativeness to some evolutions occurred in the Italian labour market and in its legislation. In common with other EU countries, Italy has indeed experienced a general trend of labour market liberalization that may have gradually reduced search and matching frictions, and eventually improved allocative efficiency. For instance, in the 1980s, hiring typically involved only open-end contracts, while hirings under temporary contracts were gradually liberalized only starting from the second half of the 1990s. Moreover, during the first years considered here, manual workers were selected almost exclusively from the unemployment workers' lists held by the public employment service, and not via direct selection mechanisms. Indeed, the hiring process was fully liberalized only in the early 1990s. Finally, other labour market tendencies have probably contributed to the growth in sorting between firm wage policies and worker skills. In particular, changes in the overall composition and characteristics of firms across time represent another potentially important channel determining this trend. ${ }^{35}$

In the next section we discuss how changes in the industrial relation system might have had a more direct bearing on the other two main findings of the paper, the declining dispersion in firm wage policies and the rising contribution of the worker-specific component of wages to the overall inequality trends. In doing so, it is useful to assess the experience of the second largest manufacturing economy in Europe in light of what has already been documented for its manufacturing leader.

\footnotetext{
${ }^{35}$ On this respect, Table 3.1 shows that the composition of employment across industries tends to be quite stable over time, although the proportion of workers in the secondary sector is slightly higher toward the end of the overall period under study. Instead, there is a persistent growth in the incidence of small-sized firms.
} 
Table 4: Variance Decomposition of Log Daily Wages, Men

\begin{tabular}{l|c|c|c|c} 
Period & $\operatorname{Var}\left(\phi_{j}\right)$ & $\operatorname{Var}\left(\eta_{i}\right)$ & $\operatorname{Var}\left(x_{i t} \beta\right)$ & $\operatorname{Var}\left(\epsilon_{i t}\right)$ \\
\hline $1982-1987$ & 0.031 & 0.050 & 0.006 & 0.008 \\
$1984-1989$ & 0.027 & 0.100 & 0.089 & 0.008 \\
$1988-1993$ & 0.026 & 0.101 & 0.094 & 0.008 \\
$1992-1997$ & 0.028 & 0.076 & 0.007 & 0.007 \\
$1996-2001$ & 0.024 & 0.130 & 0.153 & 0.007 \\
\hline \hline
\end{tabular}

\begin{tabular}{l|c|c|c|c}
\hline Period & $2 \operatorname{Cov}\left(\phi_{j}, \eta_{i}\right)$ & $2 \operatorname{Cov}\left(\phi_{j}, x_{i t} \beta\right)$ & $2 \operatorname{Cov}\left(\eta_{i}, x_{i t} \beta\right)$ & TOTAL VAR. \\
\hline $1982-1987$ & -0.020 & 0.001 & 0.007 & 0.083 \\
$1984-1989$ & -0.019 & 0.008 & -0.121 & 0.092 \\
$1988-1993$ & -0.014 & 0.015 & -0.116 & 0.113 \\
$1992-1997$ & -0.002 & 0.002 & 0.006 & 0.123 \\
$1996-2001$ & -0.006 & 0.018 & -0.195 & 0.131 \\
\hline
\end{tabular}

The estimation sample is composed of all workers in the largest connected set, provided they where employed for at least four months. Results are computed only for firms located in Veneto.

Table 5: Decomposition of the Total Wage Variance Evolution, Male Sample

\begin{tabular}{l|c|c|c|c|c} 
Period & $\operatorname{Var}\left(\phi_{j}\right)$ & $\operatorname{Var}\left(\eta_{i}+x_{i t} \beta\right)$ & $\operatorname{Var}\left(e_{i t}\right)$ & $\begin{array}{c}2 \operatorname{Cov}\left(\phi_{j}, \eta_{i}+\right. \\
\left.x_{i t} \beta\right)\end{array}$ & $\begin{array}{c}\text { TOTAL } \\
\text { VAR. }\end{array}$ \\
\hline $1982-1987$ & 0.031 & 0.063 & 0.008 & -0.019 & 0.083 \\
\% of Total & 37.3 & 75.9 & 9.6 & -22.9 & 100 \\
$1996-2001$ & 0.024 & 0.088 & 0.007 & 0.012 & 0.131 \\
\% of Total & 18.3 & 67.2 & 5.3 & 9.2 & 100 \\
\hline Difference & -0.007 & 0.025 & -0.001 & 0.031 & 0.048 \\
$\% \Delta$ & -25.5 & 33.1 & -13.3 & 200.0 & 44.9 \\
$\%$ & & & & & $\mathbf{- 2 . 1}$ \\
\hline
\end{tabular}

Percentage changes for a given quantity $z$ from $t-1$ to $t$ are computed using a reference value $z_{r}$ defined as $z_{r}=\frac{\left|z_{t}\right|+\left|z_{t-1}\right|}{2}$ 


\subsection{Wage Inequality and Institutions: A Comparative Perspective}

Since we have used a sampling strategy and a method similar to the one that has been applied by Card, Heining, and Kline [2013] on German data, it is particularly interesting to compare their evidence with that provided in our study. Table 6 reports the decomposition of equation (2) applied on the results of Card, Heining, and Kline [2013], and the results obtained by applying the same decomposition on our sample, considering a comparable period of time.

Male earning dispersion has increased in Italy at a similar pace than in West Germany. ${ }^{36}$ However, the determinants of this trend are different in the two countries. Card, Heining, and Kline [2013] show that, considering differences between the period 1996-2002 and the period 1985-1991, only $34 \%$ of the total growth in wage variance can be attributed to greater individual heterogeneity dispersion, while the same amount is more than $51 \%$ in the case of Veneto. Between the same periods firms' pay premiums dispersion rose by $26 \%$ in Germany, while it has reduced by almost $8 \%$ in our sample. They also find that the sorting between firm-specific and employee-specific pay premiums contributed for another $36 \%$ to the overall growth in the German earnings inequality. ${ }^{37}$

Card, Heining, and Kline [2013] interpret their findings, and in particular the growth in firms' wage policies dispersion, as being driven by the major changes in the German industrial relation system that occurred in the early 1990s. As discussed by Dustmann, Ludsteck, and Schnberg [2009], rather than in legislation reforms, such changes were laid out in contract and mutual agreements between the three main actors of the system: employer associations, trade unions and works councils. In response to the challenges of the post-reunification period (e.g., increasing threats of firms' off-shoring and massive migration flows), these actors allowed for an unprecedented decentralization of the

\footnotetext{
${ }^{36}$ In absolute terms, the variance of wages is higher in West Germany. However, beside differences in the definition of wages across samples, we should consider that our analysis is based on a database covering the Veneto region only. Thus, our sample is likely to be more homogeneous than the one employed by Card, Heining, and Kline [2013].

${ }^{37}$ The sorting contribution in Card, Heining, and Kline [2013] is somewhat weaker contribution than what we have found in our paper, though this might reflect the relative imprecision of the estimated correlations between between worker and firm fixed effect, as often documented by the literature estimating AKM-type models.
} 
German wage-setting process since the early 1990s. Deviations from industry-wide agreements through "opting-out", "opening" or "hardship" clauses were all increasingly used, even though the dominating system of industry-wide bargaining basically remained unchanged. ${ }^{38}$ Indeed, Card, Heining, and Kline [2013] observe that firms' pay premiums, as computed on the 1996-2002 sample, are disproportionally lower among establishments that had opted out from national collective agreements, enlarging the dispersion in the firms' wage policies. With the increase in the share of German workers not covered by any kind of union agreement, and the rise in the number of firm-level deviations from industry-wide union agreements, so did the variance of the firm-specific wage policies, $\operatorname{Var}\left(\phi_{j}\right)$.

Italy's system of industrial relations shares many features of the German one, and in particular the centrality of the industry-wide collective bargaining. However, in many respects the Italian system has not shown the flexibility demonstrated by the German system, nor have the reforms it has experienced during the mid 1990s significantly altered the system's influence on wage setting. To begin with, Italian firms have never been able to opt-out the industry-wide wage settlements and adjust wage downwardly, whenever the local or firm-specific economic conditions and competitive pressures so required (see Section 2). This may explain why, unlike the German case, the variance in the Italian firms' wage policies has not widened over time, despite the fact that also Italy has been exposed to the long-run challenges posed by the introduction of new technologies and increased international competition. $^{39}$

Notice that, according to our estimates, the variance of firm wage policies actually decreased from the mid 1980s to the early 2000s. Unable to deviate from the industry-set minimum wages, Italian firms could still resort to incremental firm-level wage bargaining as a source to differentiate their firm wage policies. Our data do not allow us to observe which firms or workers were covered by firm-level agreements. Nevertheless, the avail-

\footnotetext{
${ }^{38}$ Dustmann, Ludsteck, and Schnberg [2009] provide an in-depth discussion of these and related changes in the German system of industrial relations, and provide the relevant institutional background.

${ }^{39}$ Facilitated by the close to border location, and partly in response to competitive pressures, many Veneto firms moved their production abroad during the period considered. For example, the Romanian province of Timisoara is often called the "newest" Venetian Province, due to the large number of Veneto establishment that have opened there.
} 
able evidence suggests that the incidence of firm-level agreements declined over time (e.g., Sestito and Rossi [2000]), partly as a consequence of a reduction in unionisation rates, as shown for Veneto by Vaona [2006]. The resulting standardization of compensation schemes across employers is consistent with our finding of a decreasing dispersion in firms' pay policies. ${ }^{40}$

The gradual dismantling of several egalitarian institutions and practices, which took place during the 1980s, could be an additional channel explaining the higher variability in firm wage policies in the first years of our sample period, and its subsequent decline. During the 1970s, the excessive wage compression operated by the indexation mechanism of the Scala Mobile was distorting the wage structure defined by sectoral collective agreements. Firms which wanted to provide a more adequate remuneration to the skills of their workers, most often at the team or group level, had to adopt their own firm-specific wage policy. On this respect, the 1980s were indeed characterized by strong political pressures of white collars and intermediate managers against the excessively egalitarian policies followed by the unions. $^{41}$ As a result, starting from 1987, the renewals of sectoral collective agreements gradually broadened the gaps in the pay scale of the various livelli di inquadramento. ${ }^{42}$ Since this evolution has probably improved the signal about appropriate wage adjustments provided by the nation-wide contract, it could have also contributed to reduce the adoption of differentiated firm wage policies.

In the previous section, we noticed how the dispersion of observed and unobserved individual heterogeneity has emerged from our estimates as a major contributing factor to the overall increase in earnings inequality. While in principle these trends may reflect the underlying labour market forces, e.g. demand and supply of skills, in the following section we will argue that these market forces have been largely "channelled" into the tracks

\footnotetext{
${ }^{40}$ Another potential reason for the decline in firm-level bargaining, and hence in $\operatorname{Var}\left(\phi_{j}\right)$, is given by a documented rising incidence of small and very small firms in the Italian economy, typically those where there is no firm-level bargaining.

${ }^{41}$ One of the first and most important moments in the history of this opposition movement was the socalled march of the forty-thousands in Turin, in May 1980. This protest marked a division in trade unions, which since then were forced to take into greater consideration the interests of more qualified workers (on this topic, see Manacorda [2004] among others).

${ }^{42}$ See CESOS [1989].
} 
set by the Italian system of industrial relations, in particular through the sectoral-level bargaining process. We will do so by showing that the growth in individual heterogeneity dispersion has been almost entirely driven by the broadened differences in pay between job title categories, as settled in the industry-wide contract renewals. 
Table 6: Wage Variance Evolution in Germany and Italy

Veneto Working Histories Data, Male Sample

\begin{tabular}{l|c|c|c|c|c} 
Period & $\operatorname{Var}\left(\phi_{j}\right)$ & $\operatorname{Var}\left(\eta_{i}+x_{i t} \beta\right)$ & $\operatorname{Var}\left(e_{i t}\right)$ & $\begin{array}{c}2 \operatorname{Cov}\left(\phi_{j}, \eta_{i}+\right. \\
\left.x_{i t} \beta\right)\end{array}$ & $\begin{array}{c}\text { TOTAL } \\
\text { VAR. }\end{array}$ \\
\hline $\begin{array}{c}1984-1989 \\
\text { \% of Total }\end{array}$ & 0.027 & 0.068 & 0.008 & -0.011 & 0.092 \\
& $29.3 \%$ & $73.9 \%$ & $8.7 \%$ & $-12.0 \%$ & $100.0 \%$ \\
$1996-2001$ & 0.024 & 0.088 & 0.007 & 0.012 & 0.131 \\
$\%$ of Total & $18.3 \%$ & $67.2 \%$ & $5.3 \%$ & $9.2 \%$ & $100.0 \%$ \\
\hline $\mathbf{\%} \Delta$ & $-11.8 \%$ & $25.6 \%$ & $-13.3 \%$ & $200.0 \%$ & $35.0 \%$ \\
$\mathbf{\%} \Delta / \Delta_{\text {TOT }}$ & $\mathbf{- 7 . 7 \%}$ & $\mathbf{5 1 . 3} \%$ & $\mathbf{- 2 . 6} \%$ & $\mathbf{5 9 . 0} \%$ & $\mathbf{1 0 0 . 0} \%$ \\
\hline \hline
\end{tabular}

German IAB Data, Male Sample (from Card, Heining, and Kline [2013])

\begin{tabular}{l|c|c|c|c|c} 
Period & $\operatorname{Var}\left(\phi_{j}\right)$ & $\operatorname{Var}\left(\eta_{i}+x_{i t} \beta\right)$ & $\operatorname{Var}\left(e_{i t}\right)$ & $\begin{array}{c}2 \operatorname{Cov}\left(\phi_{j}, \eta_{i}+\right. \\
\left.x_{i t} \beta\right)\end{array}$ & $\begin{array}{c}\text { TOTAL } \\
\text { VAR. }\end{array}$ \\
\hline $\begin{array}{c}1985-1991 \\
\text { \% of Total }\end{array}$ & 0.025 & 0.095 & 0.014 & 0.005 & 0.139 \\
$18.1 \%$ & $67.9 \%$ & $10.2 \%$ & $3.8 \%$ & $100.0 \%$ \\
$1996-2002$ & 0.038 & 0.112 & 0.017 & 0.023 & 0.190 \\
$\%$ of Total & $19.9 \% \%$ & $59.0 \%$ & $8.9 \%$ & $12.3 \%$ & $100.0 \%$ \\
\hline $\mathbf{\%} \Delta$ & $39.3 \%$ & $16.6 \%$ & $17.6 \%$ & $125.5 \%$ & $30.5 \%$ \\
$\mathbf{\%} \Delta / \Delta_{\text {TOT }}$ & $\mathbf{2 4 . 6} \%$ & $\mathbf{3 4 . 2} \%$ & $\mathbf{5 . 5} \%$ & $\mathbf{3 5 . 7} \%$ & $\mathbf{1 0 0 . 0} \%$ \\
\hline \hline
\end{tabular}

Percentage changes for a given quantity $z$ from $t-1$ to $t$ are computed using a reference value $z_{r}$ defined as $z_{r}=\frac{\left|z_{t}\right|+\left|z_{t-1}\right|}{2}$ 


\subsection{An Empirical Assessment of the Impact of Collective Bargaining on Wage and Human Capital Dispersion}

In this section we show that overall pay dispersion is mostly determined by between job titles earning variability. ${ }^{43}$ We apply a simple variance decomposition methodology that allows to divide total variation of a given quantity, which is partitioned into groups (for example job titles), into an ecological component (differences between groups) and an individual component (differences between members of the same group). Keeping fixed a given period $t$, let $y_{i j}$ represent wages (or another quantity of interest) of worker $i$ in group $j$, let $n$ be the total number of workers, let $J$ be the number of groups, and let $n_{j}$ be the set of employees in group $j$. Moreover, define $\bar{y}_{j}$ as the average level of wages within group $j$, and define the within group variance as

$$
\mathrm{V}_{j}=\left(\left\|n_{j}\right\|-1\right)^{-1} \sum_{i \in n_{j}}\left(y_{i t}-\bar{y}_{j}\right)^{2}
$$

where we indicate by $\left\|n_{j}\right\|$ the cardinality of the set $n_{j}$ (i.e. the number of employees in group $j$ ). Using the above notation, we can decompose the total wage variance into a within group component, and a between group component as follows

$$
\operatorname{Var}(y)=\frac{1}{n-1}(\underbrace{\sum_{j=1}^{J}\left(\left\|n_{j}\right\|-1\right) \mathrm{V}_{j}}_{\text {within component }}+\underbrace{\sum_{j=1}^{J}\left\|n_{j}\right\|\left(\bar{y}_{j}-\bar{y}\right)^{2}}_{\text {between component }})
$$

Notice that the variance decomposition defined above can be easily applied not only on job titles but also on any other group partitioning the workers' population, such as firms. ${ }^{44} \mathrm{In}$ this section, by relying on the AKM regression results, we implement the decomposition of equation (3) on the individual-specific component of the wage, albeit for comparison we apply the same decomposition also on the raw wage. As mentioned, the term $\left(\eta_{i}+x_{i t} \beta\right)$ appearing in the AKM wage equation (which we sometimes call worker wage premium),

\footnotetext{
${ }^{43}$ In Section A.1 we also show that the segregation of high wage earners into given firms is not an important phenomenon in the Italian case. Thus, job titles are relevant in determining pay dispersion, and this is not a consequence of the fact that workers in given occupations are more likely to be hired by given groups of firms. The low level of skill segregation across firms is also documented by Iranzo, Schivardi, and Tosetti [2008].

${ }^{44}$ See Section A.1.
} 
represents a good measure of individual-specific productive abilities.

In applying the decomposition of equation (3), we have used job titles (livelli di inquadramento) to partition the population. The initial allocation of workers to a given job title is typically related to its schooling level and other time-invariant personal characteristics, captured by the worker fixed effect embedded in our estimated worker premium. The effect of promotion to higher ladders of the scale, as well as the (fairly automatic) seniority wage premiums stipulated at each ladder by the relevant collective contract, are reflected in the time-varying component of the estimated worker premium.

Notice that market forces can affect pay differentials between job titles only for what concerns the component of the wage above the minimum, which is set at the industry-wide level. Moreover, by the law, employers are not allowed to downgrade workers into less remunerative job titles, an element which provides further rigidity in firms' wage adjustment decisions. ${ }^{45}$ Given this institutional context, the between job title variance can be considered an informative parameter, which, to a given extent, allows to quantify the impact of collective bargaining on wages.

A different measure of the effect of job title membership on wages is proposed by Torres, Portugal, Addison, and Guimaraes [2013], who include job title fixed effects as regressors in an AKM model. However, in the Italian context, the chosen method is more suitable for studying the influence of collective bargaining on wage dynamics. Indeed, the proposed variance decomposition can be computed on a yearly basis. Moreover, as mentioned above, in Italy there are detailed rules, set by the relevant collective contract, for assigning each worker to a job title. Such strict criteria, which tend to be based on seniority, education and several other dimensions, change quite frequently over time. ${ }^{46}$ On this respect, a nice feature of the between job titles variance is that, when compared from year to year, it fully captures the effects of such institutionally-driven shifts in the segregation of workers with

\footnotetext{
${ }^{45}$ Nevertheless, employers can obviously affect the overall composition of job titles through their hiring policies, or by moving upward their current employees. We will propose a test for assessing the importance of these tendencies in Section A.1.

${ }^{46}$ For example, several managerial occupations have started to be regulated by autonomous industrywide collective contracts since the end of the 1980s. The resulting shift in the segregation of workers' characteristics across the occupational categories defined by collective contracts is a source of challenges on how to compare and interpret the variance of job title fixed effects across time.
} 
given characteristics across various minimum wage levels. Thus, the chosen decomposition method provides a broad and easily interpretable measure of the impact of collective bargaining on the evolution of wage inequality.

Before presenting the decomposition results, we provide further information on how job titles (livelli di inquadramento), which are specific to a given industry-wide collective contract, have been identified in the data. Several economic activities, despite being similar in their nature, can be regulated by more than one collective contract, ${ }^{47}$ and the number of such industry-wide contracts, as well as the number of job titles defined by them, can change over time. Therefore, we have not constructed a homogeneous classification of job titles across years. We have instead chosen a year-specific definition of the so-called livelli di inquadramento, which is based on their classification code. As an inclusion rule, we have adopted the criteria of considering as a legitimate job title only those for which at least 150 observations were present, in a given year, in the largest connected set of Veneto firms. ${ }^{48}$ The total number of inquadramento levels included in our decompositions ranges between 432 (in 2001) and 520 (in 1984). Moreover, the percentage of the observations belonging to the largest connected set of Veneto firms, which we have been able to include in our decompositions, ranges between $83 \%$ of the total in 2001 and $70 \%$ in 1986 .

Figure 4 reports the results of the variance decomposition into a between- and a within-job titles components, applied year-by-year on the male sample. The reference population is composed of workers in the largest connected set of Veneto firms, provided that they belong to a sufficiently representative job title category. ${ }^{49}$ The graphs show that practically all of the growth in the dispersion of wages and of workers' pay premiums is accounted for by increased variability between occupations. Indeed, both in the case of unconditional

\footnotetext{
${ }^{47}$ To give an example, there are almost 40 distinct contracts covering workers in the sea transport industry, while there are only five contracts for workers in the metal-manufacturing sector.

${ }^{48}$ This inclusion rule has been chosen to mitigate measurement error issues which are embedded in job titles' classification codes. When computing the variance decomposition using different thresholds, we did not find great sensitivity in the results. Measurement error problems are driven by the fact that job title classification codes can change from year to year, since they are set by the respective industry-wide contracts. However, this problem seems to be particularly worrying only in the year 1989, when also the industry-wide contracts' classification system was reformed.

${ }^{49}$ Given that we have divided the 1982-2001 period into overlapping panels, in some years we can have two distinct mobility groups. Since there are no major differences when adopting different rules, we always choose to consider only the connected set of the latest panel.
} 
wages and of individual heterogeneity, the between component of the total variance shows a growing trend, with the partial exception of the second half of the 1990s, while the within component is persistently flat. ${ }^{50}$ As a consequence, in relative terms this latter source of variation looses importance as a determinant of overall inequality. Figure 5 reports the evolution of between- and within-job titles workers' wage premiums dispersion by sector (secondary and tertiary) and by occupation (white and blue collars), computed by normalizing the 1982 levels of dispersion to $100 .{ }^{51} \mathrm{~A}$ trend similar to the one implied by the right panel of Figure 4 is observed for all categories of workers. However the growth of between job titles dispersion in human capital is stronger among production workers and in the manufacturing sector.

A potential explanation for the trend toward higher between-job titles differences in wages could be that firms have increasingly assigned employees to higher inquadramento levels, as a way to raise the base wage of highly-skilled and performing workers. In Section A.1 we show that the role of this re-assignment has been relatively limited, as it can explain only a modest proportion of the between job-title variance displayed in Figure $4{ }^{52}$

The results presented in this section, together with the supplementary analysis of Section A.1, show that almost all of the inequality growth has arisen from differences in pay between job categories which are defined and protected by the industry-wide collective agreements. It remains unclear whether institutions have simply reacted to market forces, and the extent to which they have represented a distortion to the wage structure. Nevertheless, we can conclude that the growth in Italian wage inequality has been allowed by the opening of the pay gaps between the various livelli di inquadramento stipulated at each contract renewal, combined with the gradual dismantling of the egalitarian wage indexation system since the mid 1980s.

\footnotetext{
${ }^{50}$ An exception to this general trend is the year 1989, during which there is a drop in the within component of the total variance. However, this outcome is probably due to the measurement error induced by the mentioned change in the contracts classification code, which occurred that year.

${ }^{51}$ By secondary sector, we define manufacturing and constructions sector. The primary sector (agriculture, forestry, fishing and mining) is excluded from these computations. The service sector is defined as the residual category.

${ }^{52}$ Notice that, as mentioned, this re-assignment can only be operated upwardly, i.e. it is not possible to downgrade a worker to a lower livello di inquadramento.
} 
Figure 4: Decomposition of Unconditional Wage Variance and Workers' Wage Premiums Variance Within- and Between Job Titles Defined by Sector-Wide Contracts
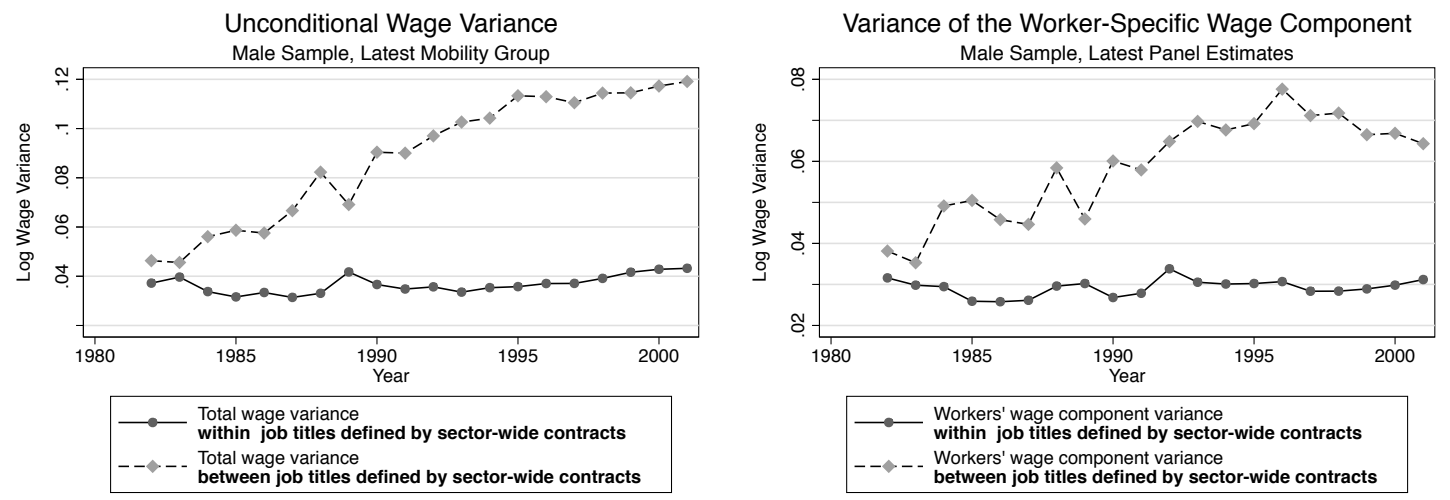

Job titles (inquadramento levels) are occupational categories defined within each sector-wide collective contract. Their definition might change at every round of negotiation. For each job title, there are a related minimum wage and a related seniority premium that are bargained at the sector-wide level. In each year, we have selected only job titles represented by at least 150 workers in the largest connected set of Veneto firms. Depending on the year, the number of distinct job titles considered ranges between 432 (in 2001) and 520 (in 1984).

Figure 5: Evolution of Workers' Wage Premiums Variance Within- and Between Job Titles by Sector and Occupation

Evolution of Workers' Wage Component Variance by Sector $1982=100$

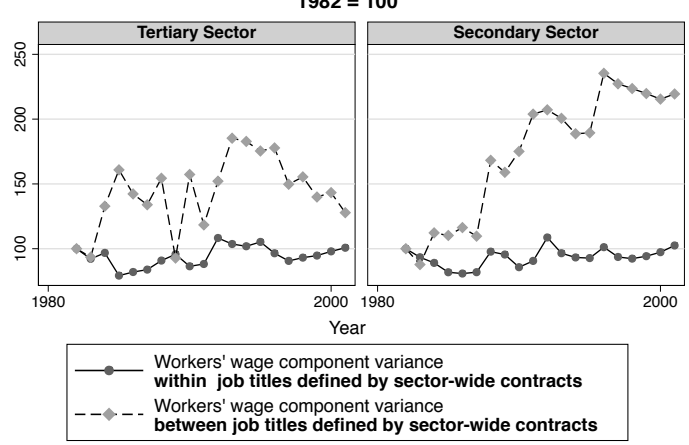

Evolution of Workers' Wage Component Variance by Occupation

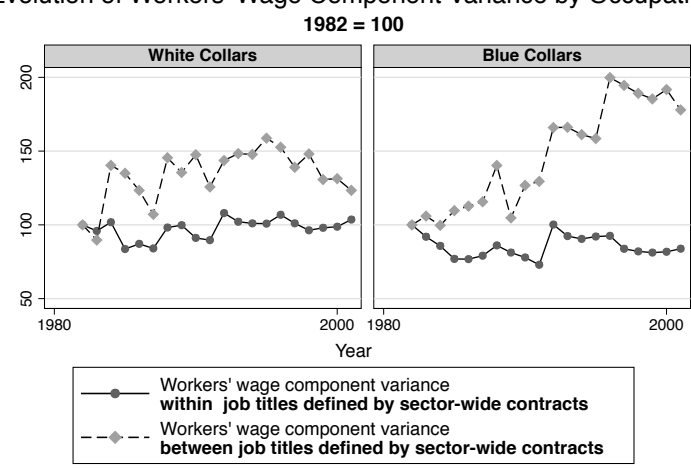




\section{Conclusions}

In this paper we have analysed the evolution of Italian wage inequality over a two decade period. We have documented a substantial growth in several measures of pay dispersion. To interpret this trend, we have decomposed the overall wage dispersion in the components capturing heterogeneity in firm pay policies, heterogeneity in workers' timevarying and time-constant characteristics, as well as the sorting patterns between the firms' and workers' specific components of wages. To do so, we have estimated two-way fixed effect wage models over subsequent time intervals, and have used matched employeremployee data covering the population of private sector firms and workers in the Veneto region of Italy. We have found that earnings dispersion has been mostly driven by differences in the worker-specific components of wages. Instead, in Italy employer-specific pay premiums have lost relevance over time.

Our results are different from evidences documented for other countries, and Germany in particular. In this respect, we have provided an indirect support to the claims of Card, Heining, and Kline [2013]. These authors report evidence of a rise in the dispersion of firms' pay premiums. They attribute this finding to a growth in firm-level deviations from the dispositions of industry-wide collective agreements (e.g., the opting-out clauses), which were allowed by the German system and became increasingly used since the mid 1990s. We have documented the lack of such a flexible adaptation process in a similar manufacturing-oriented economy, which has undergone qualitatively different reforms in its system of industrial relations. Italian firms have been unable to apply heterogeneous pay policies, and to circumvent the constraints to wage dynamics imposed by the sectoral level of bargaining.

To shed further light on the role played by collective bargaining in the observed inequality trend, we have analysed the evolution of pay differentials across so-called livelli di inquadramento. These are job titles defined by nation-wide sectoral collective agreements, for which a set of minimum wages holds and applies regardless of a worker's union membership. A simple variance-decomposition exercise allowed us to show that the growth in both, wage and human capital dispersion, has almost entirely occurred between such job 
titles.

Overall, our results show that market forces have been largely "channelled" into the tight tracks set by the rules governing the country's fairly centralized system of industrial relations. Moreover, during the overall period considered, firms have been granted very limited margins of wage flexibility. The extent to which the bargaining system may have been able to provide the adequate signals about the appropriate wage adjustments, i.e. the adjustment required by underlying market forces, remains an open question.

\section{References}

Abowd, J., F. Kramarz, and D. Margolis (1999): "High Wage Workers and High Wage Firms," Econometrica, 67(2), 251-333.

Abowd, J. M., R. H. Creecy, and F. Kramarz (2002): "Computing Person and Firm Effects Using Linked Longitudinal Employer-Employee Data," Longitudinal EmployerHousehold Dynamics Technical Papers 2002-06, Center for Economic Studies, U.S. Census Bureau.

Acemoglu, D., And D. Autor (2011): Skills, Tasks and Technologies: Implications for Employment and Earningsvol. 4 of Handbook of Labor Economics, chap. 12, pp. 1043-1171. Elsevier.

Akerlof, G. A. (1982): "Labor Contracts as Partial Gift Exchange," The Quarterly Journal of Economics, 97(4), 543-69.

Andrews, M. J., L. Gill, T. Schank, and R. Upward (2008): "High Wage Workers and Low Wage Firms: Negative Assortative Matching or Limited Mobility Bias?," Journal of the Royal Statistical Society Series A, 171(3), 673-697.

Autor, D. H., L. F. Katz, and M. S. Kearney (2008): "Trends in U.S. Wage Inequality: Revising the Revisionists," The Review of Economics and Statistics, 90(2), $300-323$.

Brandolini, A., P. Cipollone, and P. Sestito (2002): "Earnings Dispersion, Low 
Pay and Household Poverty in Italy, 1977-1998," in The Economics of Rising Inequalities. Oxford University Press.

Burdett, K., And D. T. Mortensen (1998): "Wage Differentials, Employer Size, and Unemployment," International Economic Review, 39(2), 257-73.

Cappellari, L. (2004): “The Dynamics and Inequality of Italian Men's Earnings: Longterm Changes or Transitory Fluctuations?," Journal of Human Resources, 39(2), 475499.

Cappellari, L., And M. Leonardi (2016): "Earnings Instability and Tenure," The Scandinavian Journal of Economics, 118(2), 202-234.

Card, D., A. R. Cardoso, and P. Kline (2016): "Bargaining, Sorting, and the Gender Wage Gap: Quantifying the Impact of Firms on the Relative Pay of Women," The Quarterly Journal of Economics, 131(2), 633-686.

Card, D., F. Devicienti, and A. Maida (2014): "Rent-sharing, Holdup, and Wages: Evidence from Matched Panel Data," Review of Economic Studies, 81(1), 84-111.

Card, D., J. Heining, and P. Kline (2013): "Workplace Heterogeneity and the Rise of West German Wage Inequality," The Quarterly Journal of Economics, 128(3), 9671015 .

Casadio, P. (2003): "Wage Formation in the Italian Private Sector after the 1992-93 Income Policy Agreements," in Institutions and Wage Formation in the New Europe. Edward Elgar.

CESOS (1989): "Le relazioni sindacali in Italia, Rapporto 1987-1988," Edizioni lavoro, CESOS.

Dell'Aringa, C., and C. Lucifora (1994): "Collective Bargaining and Relative Earnings in Italy," European Journal of Political Economy, 10(4), 727-747.

Dell'Aringa, C., C. Lucifora, and N. Orlando (2005): "Collective Bargaining 
and Within-Establishment Pay Inequality in Italy," Rivista Internazionale di Scienze Sociali, 113(2), 241-265.

Devicienti, F., And A. Borgarello (2001): "Trends in the Italian Earnings Distribution, 1985-1996," LABORatorio R. Revelli Working Papers Series 2, LABORatorio R. Revelli, Centre for Employment Studies.

Devicienti, F., A. Maida, And L. Pacelli (2008): "The Resurrection of the Italian Wage Curve," Economics Letters, 98(3), 335-341.

Di Nardo, J., N. Fortin, And T. Lemieux (1996): "Labor Market Institutions and the Distribution of Wages, 1973-1992: A Semiparametric Approach," Econometrica, 64(5), $1001-1044$.

Dunne, T., L. Foster, J. Haltiwanger, and K. R. Troske (2004): "Wage and Productivity Dispersion in United States Manufacturing: The Role of Computer Investment," Journal of Labor Economics, 22(2), 397-430.

Dustmann, C., B. Fitzenberger, U. Schonberg, and A. Spitz-Oener (2014): "From Sick Man of Europe to Economic Superstar: Germany's Resurgent Economy," Journal of Economic Perspectives, 28(1), 167-88.

Dustmann, C., J. Ludsteck, and U. Schnberg (2009): "Revisiting the German Wage Structure," The Quarterly Journal of Economics, 124(2), 843-881.

Eeckhout, J., And P. Kircher (2011): "Identifying Sorting-In Theory," Review of Economic Studies, 78(3), 872-906.

ERICKSOn, C., AND A. IChino (1995): "Wage Differentials in Italy: Market Forces, Institutions, and Inflation," in Differences and Changes in Wage Structures, NBER Chapters, pp. 265-306. National Bureau of Economic Research, Inc.

Faggio, G., K. G. Salvanes, and J. V. Reenen (2010): “The Evolution of Inequality in Productivity and Wages: Panel Data Evidence," Industrial and Corporate Change, 19(6), 1919-1951. 
Flabbi, L., M. Macis, A. Moro, and F. Schivardi (2014): "Do Female Executives Make a Difference? The Impact of Female Leadership on Gender Gaps and Firm Performance," IZA Discussion Papers 8602, Institute for the Study of Labor (IZA).

Fox, J. T. (2009): "Firm-Size Wage Gaps, Job Responsibility, and Hierarchical Matching," Journal of Labor Economics, 27(1), 83-126.

Iranzo, S., F. Schivardi, and E. Tosetti (2008): "Skill Dispersion and Firm Productivity: An Analysis with Employer-Employee Matched Data," Journal of Labor Economics, 26(2), 247-285.

Katz, L. F., And K. M. Murphy (1992): "Changes in Relative Wages, 1963-1987: Supply and Demand Factors," The Quarterly Journal of Economics, 107(1), 35-78.

Leonardi, M., M. Pellizzari, and D. Tabasso (2015): "Wage Compression within the Firm," IZA Discussion Papers 9254, Institute for the Study of Labor (IZA).

Manacorda, M. (2004): "Can the Scala Mobile Explain the Fall and Rise of Earnings Inequality in Italy? A Semiparametric Analysis, 1977-1993," Journal of Labor Economics, $22(3), 585-614$.

Naticchioni, P., And A. Ricci (2009): "Falling Educational Wage Premia in Italy," QA - Rivista dell'Associazione Rossi-Doria, 4.

Piketty, T., And E. SAEz (2003): "Income Inequality In The United States, 1913-1998," The Quarterly Journal of Economics, 118(1), 1-39.

(2006): "The Evolution of Top Incomes: A Historical and International Perspective," American Economic Review, 96(2), 200-205.

Scoppa, V. (2014): "Firm Size and Wages in Italy: Evidence from Exogenous Job Displacements," Manchester School, 82(6), 677-700.

Sestito, P., And F. Rossi (2000): "Contrattazione aziendale, struttura negoziale e determinazione decentrata del salario," Lavoro e Relazioni Industriali, 2, 129-183. 
Skans, O. N., P.-A. Edin, And B. Holmlund (2009): "Wage Dispersion Between and Within Plants: Sweden 1985-2000," in The Structure of Wages: An International Comparison, NBER Chapters, pp. 217-260. National Bureau of Economic Research, Inc.

Torres, S., P. Portugal, J. T. Addison, and P. Guimaraes (2013): "The Sources of Wage Variation: A Three-Way High-Dimensional Fixed Effects Regression Model," IZA Discussion Papers 7276, Institute for the Study of Labor (IZA).

VAONA, A. (2006): "L'evoluzione recente dei tassi di sindacalizzazione in Veneto," Quaderni di Rassegna Sindacale, 3. 


\section{A. Appendix}

\section{A.1. Related Evidence on Between Job Titles Pay Dispersion}

In this section we provide further evidences related to the evolution of wage inequalities between the so-called livelli di inquadramento. In particular, we test whether this type of dispersion has been driven by a trend in the composition of the labour force, which could have become more likely to be employed at relatively low-paid (or high paid) occupations. Moreover, we test whether differences in wages and human capital arise mostly within or between firms. The analysis of this section shows that there have not been major shifts in the labour force composition, with the only exception of a small but persistent growth of low-paid occupations in the service sector. Moreover, we show that the wage and human capital dispersion has been growing more rapidly within firms.

Figure A.1 shows the proportion of workers within each quartile of the job titles' average pay distribution. In constructing the graph, we have computed year-by-year the average wage within each job title, separately considering workers in the secondary and tertiary sectors. For each of these two sectors, we have classified each job title according to the quartile of the job titles' average pay distribution to which it belongs. ${ }^{53}$ Then, we have computed year-by-year the proportion of workers within each quartile group of job titles. Figure A.1 shows that the proportion of workers within each quartile of the job title distribution has been fairly constant during the overall period considered. There are some exception to this general trend. In particular, in the years 1982 and 1983 the proportion of workers in the two lowest quartiles of the job title distribution was substantially higher than in subsequent years. Moreover, during the years between 1984 and the beginning of the 1990s, both in the secondary and tertiary sectors there is a growth in the proportion of workers in the highest quartile of job titles. However, at least in the secondary sector, this tendency is only cyclical, given that, from the early 1990s onwards, this same proportion decreases to levels similar to the ones in place during the early 1980s. Finally, in the service sector only, there is a relatively persistent growth of the proportion of workers

\footnotetext{
${ }^{53}$ The job titles' average pay distribution is not weighted by the number of observations within each job title category. Thus a given percentile of the job titles' average pay distribution can be quite different from the same percentile of the wage distribution.
} 
belonging to the lowest quartile of the job title distribution. However, this growth is quite small in magnitude. Other discrepancies in the proportions reported in the figure tend to be year-specific, and are most likely attributable to differences in the job title classification codes from one year to the other.

In Figure A.2 we replicate the analysis described above, this time considering the workerspecific component of the wage, as estimated by the AKM regression model. In particular, we have computed the average level of skills (i.e. observed and unobserved individual heterogeneity) within each job title. We have used this information to rank job titles into quartiles, and we have computed the proportion of workers within each quartile group.

Figure A.2 shows tendencies similar to the ones described in Figure A.1. However, in this case the growth in the proportion of workers belonging to the first quartile of job titles in the service sector is even stronger. Moreover, the years 1982 and 1983 are quite peculiar. Indeed, during these two years the proportion of secondary sector workers belonging to the upper quartiles of the job title distribution is quite low. This tendency is probably induced by the wage adjustment mechanisms in place up until 1984, which were shifting upward wages at the bottom of the pay scale. Other trends seem to be either year specific, or relatively small in magnitude.

Overall, by analysing the composition of job title categories across time, we can conclude that the growth in wage inequality described throughout the paper is not driven by a qualitative shift in the labour demand, from evenly remunerated occupations to professional positions characterized by a more differentiated pay structure. Instead, the channel driving the greater wage dispersion is more linked to differences in how the same occupations are rewarded across time. Thus, with the partial exception of the service sector, where employers have become more likely to hire workers belonging to less remunerative job title categories, there is no evidence of a process of polarization of the workforce.

The growth of pay differentials between job titles, which we have documented in Section 5.3 , could also derive from a process of segregation of the more qualified workers into given enclaves of firms. Such market-driven process would then probably be reflected in collective bargaining dynamics, given that the more skill-intensive firms could be able to 
grant better economic conditions to selected groups of job titles. On the other hand, if pay differentials between firms are low, despite a general growth in job title heterogeneity, we may think that firms are constrained by the sectoral bargaining standards, given that most of the inequality growth occurs within establishments, instead of across them. We now turn to this problem of determining whether, over the years, the best paid occupations have become more segregated across given groups of employers. In order to test this hypothesis, we have computed year-by-year the decompositions of equation (3), this time using firms as the partitioning group of the population.

Figure A.3 reports the within- and between-firms variance decomposition, applied on wages and on the estimated individual heterogeneity of the workforce. The reference population is composed of male workers in Veneto firms belonging to the largest connected set. The left panel of the figure shows that wage variation was almost equally split into a withinand a between-firms component during the early 1980s. Since then, the importance of earnings variance among co-workers rises sharply with respect to differences in average wages between plants. Nevertheless, the years under study are characterized also by a small growth in the unconditional wage variance between firms. This latter process can be mostly ascribed to increased sorting of workers' wage premiums with firms' pay premiums, a result which emerged from the AKM variance decomposition.

In the right panel of Figure A.3 we compute the same variance decomposition using workers' wage premiums alone, instead of total wages. ${ }^{54}$ When considering this component of the pay, we find that between-firms dispersion in human capital has even declined over the entire period. Therefore, we find no evidence of greater segregation of workers' skills across employers.

The low level of between-firms pay dispersion documented here is coherent with previous studies on Italy (such as Iranzo, Schivardi, and Tosetti [2008]), but it is a quite peculiar result when compared with evidences available for other European countries and the US. ${ }^{55}$

\footnotetext{
${ }^{54}$ Notice that despite the fact that observed and unobserved individual heterogeneity is a component of the total wage, its variance can be higher than the variance of unconditional wages, since the former does not take into account the potential negative sorting of workers' wage premiums with firms' pay premiums.

${ }^{55}$ Among studies focusing on between-plant wage inequality in other countries, see for example Dunne, Foster, Haltiwanger, and Troske [2004] on the US, Faggio, Salvanes, and Reenen [2010] on UK, and
} 
Moreover, our finding is particularly robust, given that the sample includes also very small firms and the private service sector, which are two categories whose exclusion could drive the estimates of between-plants pay differentials down. ${ }^{56}$

Overall Italy is not characterized by strong pay differences between firms, which could have been relevant if, for example, greater dispersion in productive performance across employers, often considered an outcome of technological changes and international competition, had induced greater heterogeneity in wages between plants. Instead, the relevance of pay dispersion between job titles, which is documented by Figure 4, suggests that, in the Italian case, the growth of inequality has entirely occurred within the collective bargaining framework. Based on our results, we can conclude that over the years such institution has granted more heterogeneous conditions for selected categories of workers (i.e. job titles), while it has provided limited margins of flexibility for the firms.

Skans, Edin, and Holmlund [2009] on Sweden. All of these studies document increasing between-plant wage inequality, but they do not control for non-random assignment of workers to firms. As previously discussed, Card, Heining, and Kline [2013] show that in Germany also firms pay premiums dispersion, which is a measure of between-plant wage variability net of employees' sorting, has risen over time.

${ }^{56} \mathrm{On}$ this topic, it has been documented for several countries that there is a firm-size wage premium (e.g. Fox [2009] for US and Sweden and Scoppa [2014] for Italy), so that excluding firms below a given threshold could lead to an underestimation of between plants wage differentials. Moreover, Dell'Aringa, Lucifora, and Orlando [2005], studying a sample of Italian firms in 1995, show that within establishments pay dispersion is increasing with firm size. Finally, Faggio, Salvanes, and Reenen [2010] show that UK between plants wage dispersion is more relevant in the private service sector than in the manufacturing sector. 
Figure A.1: Evolution of the Proportion of Workers Within Quartiles of the Job Titles' Average Skills Distribution

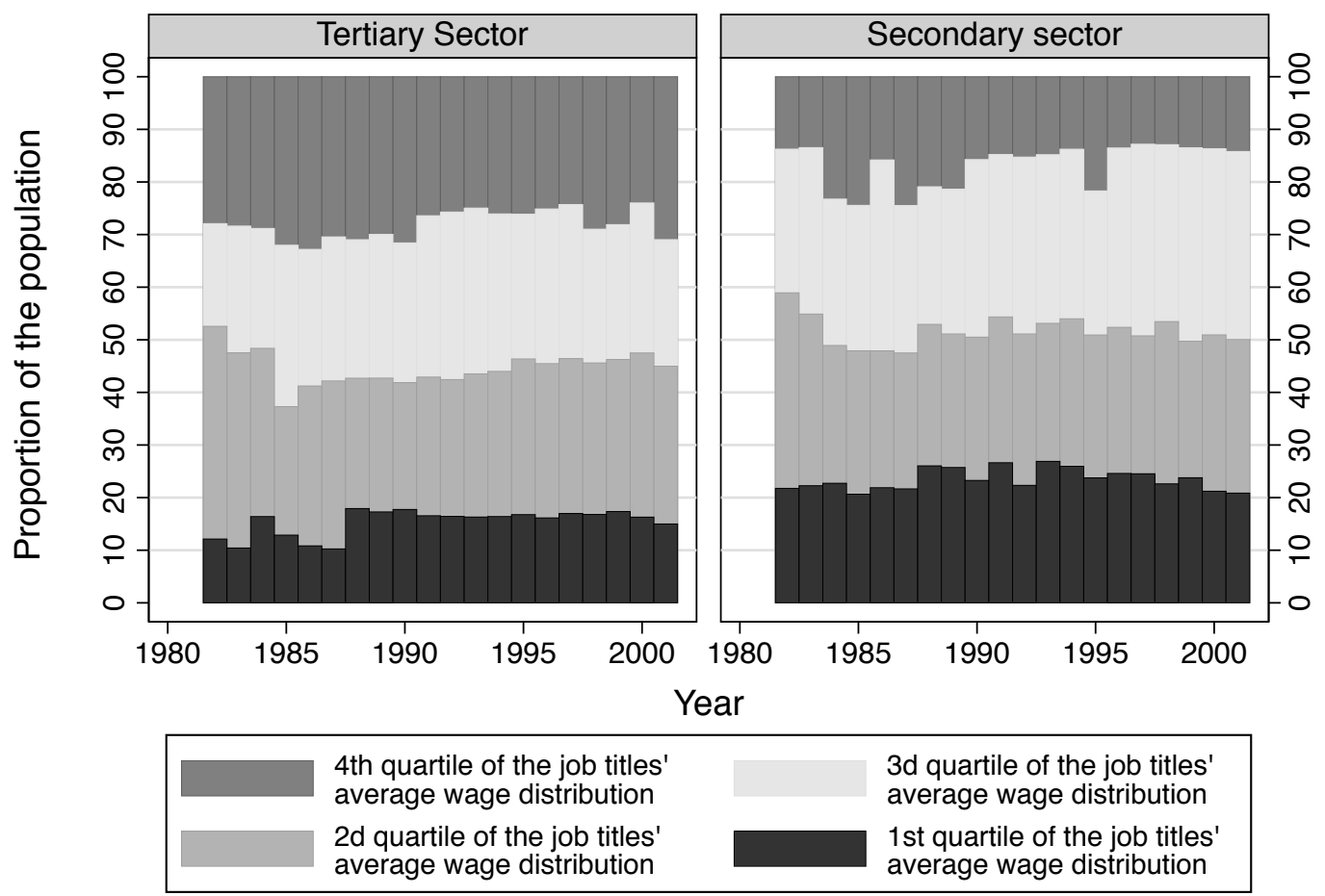

The 1st quartile refers to the bottom 25th percentiles of the job titles' average pay distribution. Similarly, the 4 th quartile refers to job titles characterized by an average wage higher than the 75 th percentile of the job titles' average pay distribution. 
Figure A.2: Evolution of the Proportion of Workers Within Quartiles of the Job Titles' Average Pay Distribution

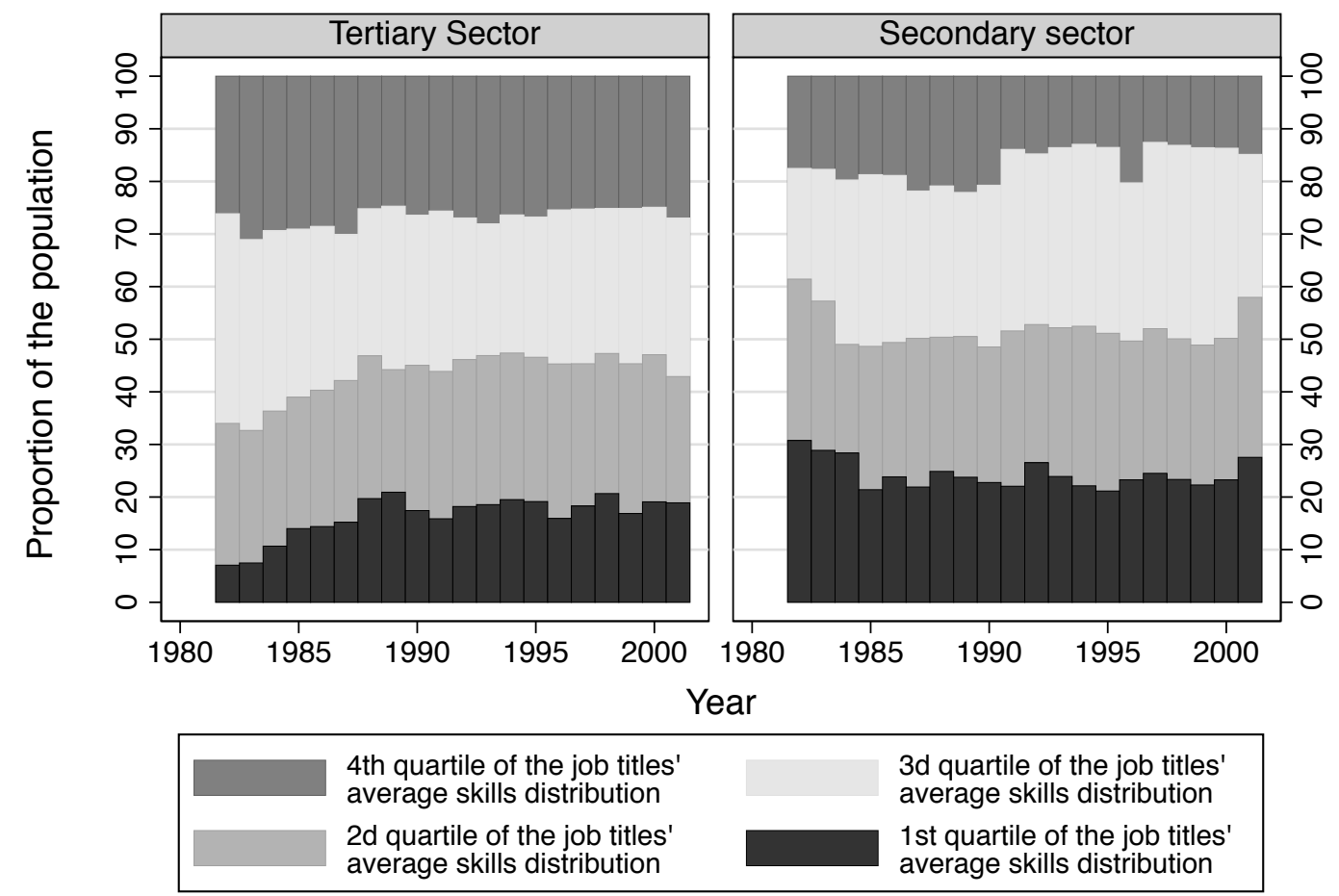

The 1st quartile refers to the bottom 25th percentiles of the job titles' average skill distribution. Similarly, the 4th quartile refers to job titles characterized by an average level of the worker specific wage component higher than the 75 th percentile of the job titles' average skill distribution.

Figure A.3: Within- and Between-Firms Decomposition of Unconditional Wage Variance and Workers' Wage Premiums Variance
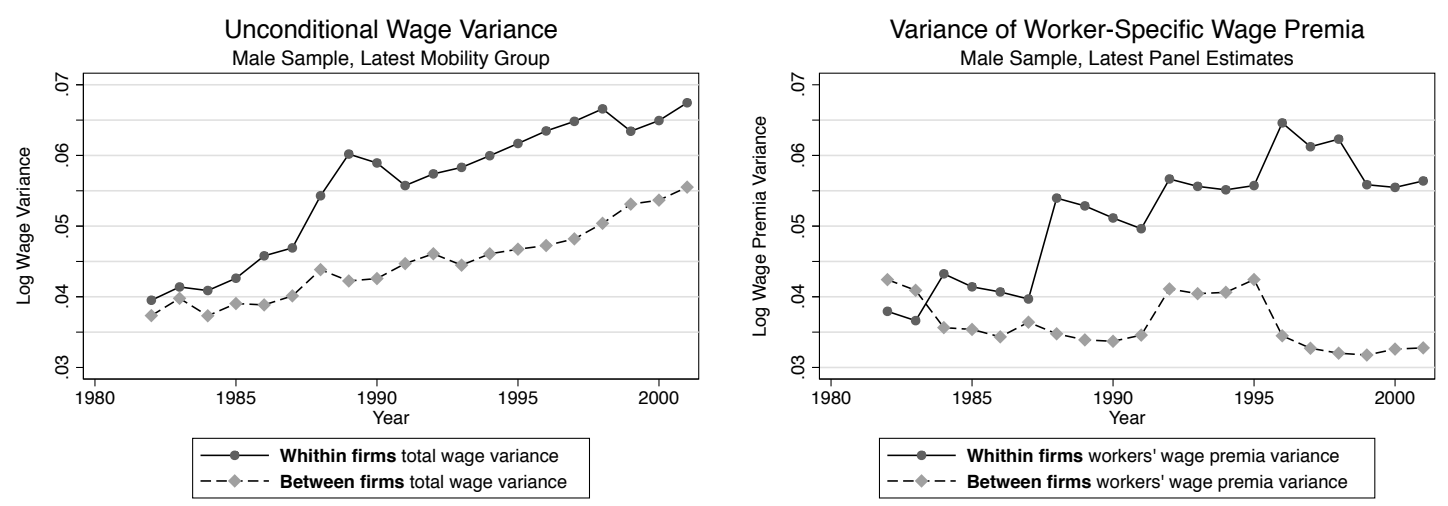

Worker's wage premiums variance is defined as $\operatorname{Var}\left(\eta_{i}+x_{i t} \beta\right)$. Since each panel that we have constructed is partially overlapping, for each year we report only estimates of $\operatorname{Var}\left(\eta_{i}+x_{i t} \beta\right)$ from the latest available period. For each year, the unconditional wage variance is computed on the largest connected set in the latest panel. Only firms located in Veneto are considered. 


\section{A.2. AKM Variance Decomposition on the Female Sample}

In this section, we provide a brief overview of the results obtained by applying the variance decomposition model of equations (1) and (2) on the female sample. As mentioned, we find substantial gender differences in the wage structure. Moreover, several reasons make it difficult to compare results obtained in the female and male samples. First of all, the Italian labour market is characterized by a much lower female participation with respect to males, especially in earliest years considered here. ${ }^{57}$ The low female participation leads to a selection bias of both, female workers and firms with higher levels of female employment. Moreover, since we do not observe the number of working hours, the influence of part-time contracts on the female wage structure tends to be quite strong, as can be inferred from the negative growth of women's wages at the 10th percentile of the pay distribution (see Figure 1). Also in this case, it is likely that firms offering part time contracts tend to be a selected category, thus making it more difficult to interpret results obtained in a regression that controls for firms wage policies.

Table A.1 reports the weighted proportion of job-to-job mobility episodes over the total number of female employees ever working at each firm. This statistic is slightly lower than in the case of males, and it tends to grow over time. Results of the AKM regression based variance decomposition, when applied on female workers, are reported in Tables A.2 and A.3. Women experienced a growth in total wage variance much higher than men, with an increase of almost $57 \%$ from the earliest to the most recent panel. In this case, dispersion of firms' pay premiums tends to be more relevant than in the male sample, but its importance clearly declines over time, and is also mitigated by the negative covariance with employees' unobserved heterogeneity. Indeed, there is a considerable amount of negative sorting between workers and firms, but, as was the case for men, this component of wage variation tends to increase over time. Over time, the female wage distribution becomes more similar to the male one. However, several differences are quite persistent. In particular, firms' wage policies are always negatively correlated with individual observable

\footnotetext{
${ }^{57}$ Indeed, total female employment has grown by almost $50 \%$ during the overall period analysed here, while it has grown much less in the male sample (see Figure A.5)
} 
and unobservable heterogeneity. This outcome can be interpreted as evidence of a limited mobility bias in the case of women, but it also may be a consequence of the fact that those firms offering part-time contracts, which tend to attract more women, are a selected category in terms of rent-sharing behaviour. Finally, notice that the importance of the idiosyncratic error term, which can be interpreted as the unexplained component of wage variation, is greater in the case of women. ${ }^{58}$

Overall, even if the order of magnitude of each element of the regression model is quite different between the male and female samples, when looking at the evolution of such components over time, a qualitatively similar pattern emerges. In both cases, the growth of wage inequality is driven, at least in part, by a more positive covariance between firms' pay policy and individual heterogeneity. Moreover, this growth is accompanied by a reduction in the dispersion of firms' fixed effects. However, in the case of women, there are no evidences of a growth in the dispersion of individual observed and unobserved heterogeneity.

\footnotetext{
${ }^{58}$ The overall $\mathrm{R}$ squared ranges between 0.69 and 0.77 in the male sample, and between 0.62 and 0.69 in the female sample.
} 
Table A.1: Proportion of Job Mobility Episodes per Firm, Female Sample

\begin{tabular}{l|c|c|c|c} 
Period & Mean & $\begin{array}{c}\text { 10th } \\
\text { Percentile }\end{array}$ & $\begin{array}{c}\text { 50th } \\
\text { Percentile }\end{array}$ & $\begin{array}{c}\text { 90th } \\
\text { Percentile }\end{array}$ \\
\hline 1982-1987 & 0.433 & 0.101 & 0.364 & 0.861 \\
$1984-1989$ & 0.474 & 0.138 & 0.429 & 0.900 \\
$1988-1993$ & 0.546 & 0.190 & 0.506 & 0.944 \\
$1992-1997$ & 0.591 & 0.222 & 0.574 & 0.954 \\
$1996-2001$ & 0.581 & 0.235 & 0.571 & 0.950 \\
\hline \hline
\end{tabular}

The statistics refer to the proportion of individuals experiencing job-to-job transitions over the total number of individuals ever working at the firm during the 6-year period. Each statistic is weighted for the number of individuals ever employed by the firm. Only firms of Veneto belonging to the largest connected set are considered.

Table A.2: Variance Decomposition of Log Daily Wages, Women

\begin{tabular}{l|c|c|c|c} 
Period & $\operatorname{Var}\left(\phi_{j}\right)$ & $\operatorname{Var}\left(\eta_{i}\right)$ & $\operatorname{Var}\left(x_{i t} \beta\right)$ & $\operatorname{Var}\left(\epsilon_{i t}\right)$ \\
\hline $1982-1987$ & 0.080 & 0.095 & 0.002 & 0.012 \\
$1984-1989$ & 0.049 & 0.097 & 0.047 & 0.011 \\
$1988-1993$ & 0.032 & 0.058 & 0.029 & 0.011 \\
$1992-1997$ & 0.035 & 0.059 & 0.025 & 0.011 \\
$1996-2001$ & 0.044 & 0.096 & 0.062 & 0.014 \\
\hline \hline
\end{tabular}

\begin{tabular}{l|c|c|c|c} 
Period & $2 \operatorname{Cov}\left(\phi_{j}, \eta_{i}\right)$ & $2 \operatorname{Cov}\left(\phi_{j}, x_{i t} \beta\right)$ & $2 \operatorname{Cov}\left(\eta_{i}, x_{i t} \beta\right)$ & TOTAL VAR. \\
\hline $1982-1987$ & -0.114 & 0.001 & 0.001 & 0.077 \\
$1984-1989$ & -0.054 & 0.002 & -0.076 & 0.076 \\
$1988-1993$ & -0.014 & 0.009 & -0.025 & 0.100 \\
$1992-1997$ & -0.007 & 0.006 & -0.010 & 0.119 \\
$1996-2001$ & -0.030 & 0.014 & -0.062 & 0.138 \\
\hline \hline
\end{tabular}

The estimation sample is composed of all workers in the largest connected set, provided they where employed for at least four months. Results are computed only for firms located in Veneto. 
Table A.3: Decomposition of the Total Wage Variance Evolution, Female Sample

\begin{tabular}{l|c|c|c|c|c} 
Period & $\operatorname{Var}\left(\phi_{j}\right)$ & $\operatorname{Var}\left(\eta_{i}+x_{i t} \beta\right)$ & $\operatorname{Var}\left(e_{i t}\right)$ & $\begin{array}{c}2 \operatorname{Cov}\left(\phi_{j}, \eta_{i}+\right. \\
\left.x_{i t} \beta\right)\end{array}$ & $\begin{array}{c}\text { TOTAL } \\
\text { VAR. }\end{array}$ \\
\hline 1982-1987 & 0.080 & 0.098 & 0.012 & -0.113 & 0.077 \\
\% of Total & 103.9 & 127.3 & 15.6 & -146.7 & 100 \\
1996-2001 & 0.044 & 0.096 & 0.014 & -0.016 & 0.138 \\
\% of Total & 31.9 & 69.6 & 10.1 & -11.6 & 100 \\
\hline Difference & -0.036 & -0.002 & 0.002 & 0.097 & 0.061 \\
$\% \Delta$ & -58.1 & -2.1 & 15.4 & 150.4 & 56.7 \\
$\% \Delta / \Delta_{T O T}$ & $\mathbf{- 5 9 . 0}$ & $\mathbf{- 3 . 3}$ & $\mathbf{3 . 3}$ & $\mathbf{1 5 9 . 0}$ & $\mathbf{1 0 0 . 0}$ \\
\hline \hline
\end{tabular}

Percentage changes for a given quantity $z$ from $t-1$ to $t$ are computed using a reference value $z_{r}$ defined as $z_{r}=\frac{\left|z_{t}\right|+\left|z_{t-1}\right|}{2}$ 
Figure A.4: Evolution of GDP in Italy and North-Eastern Italy

Evolution of GDP 1980 - 2001

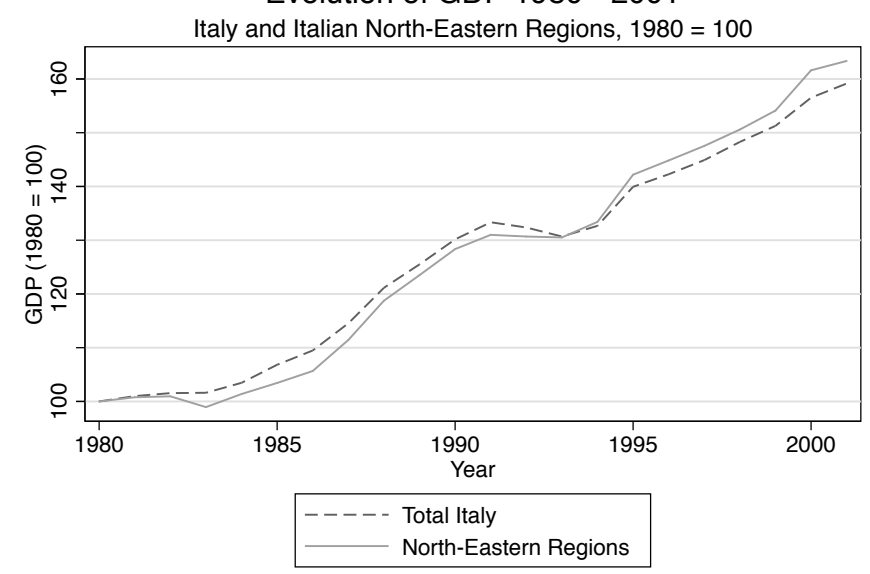

Source: ISTAT (Italian Statistical Office)

Figure A.5: Evolution of Absolute Employment in Veneto's Private-Sector Firms

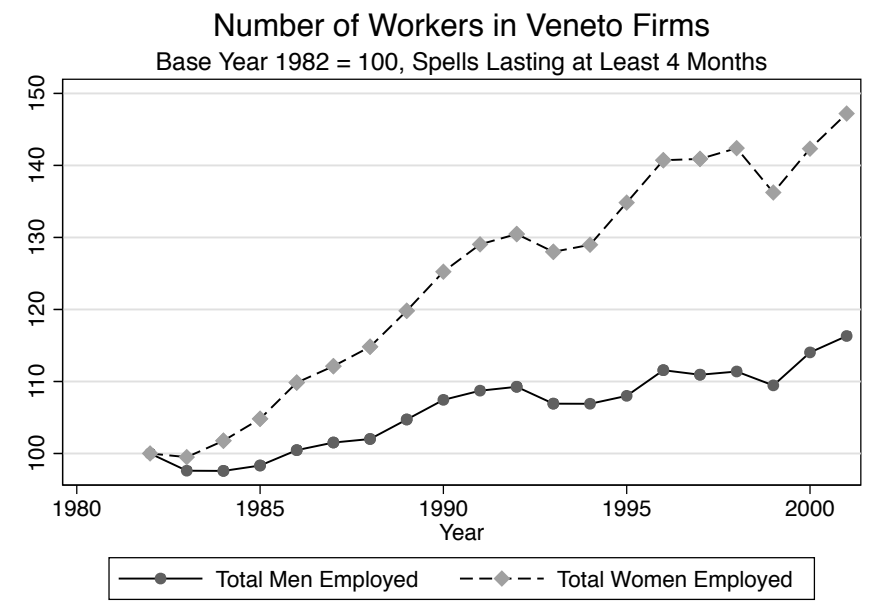


Figure A.6: Long-Run Evolution of Gross Weekly Wages

Real-Level Average and St. Dev. of Log Wages
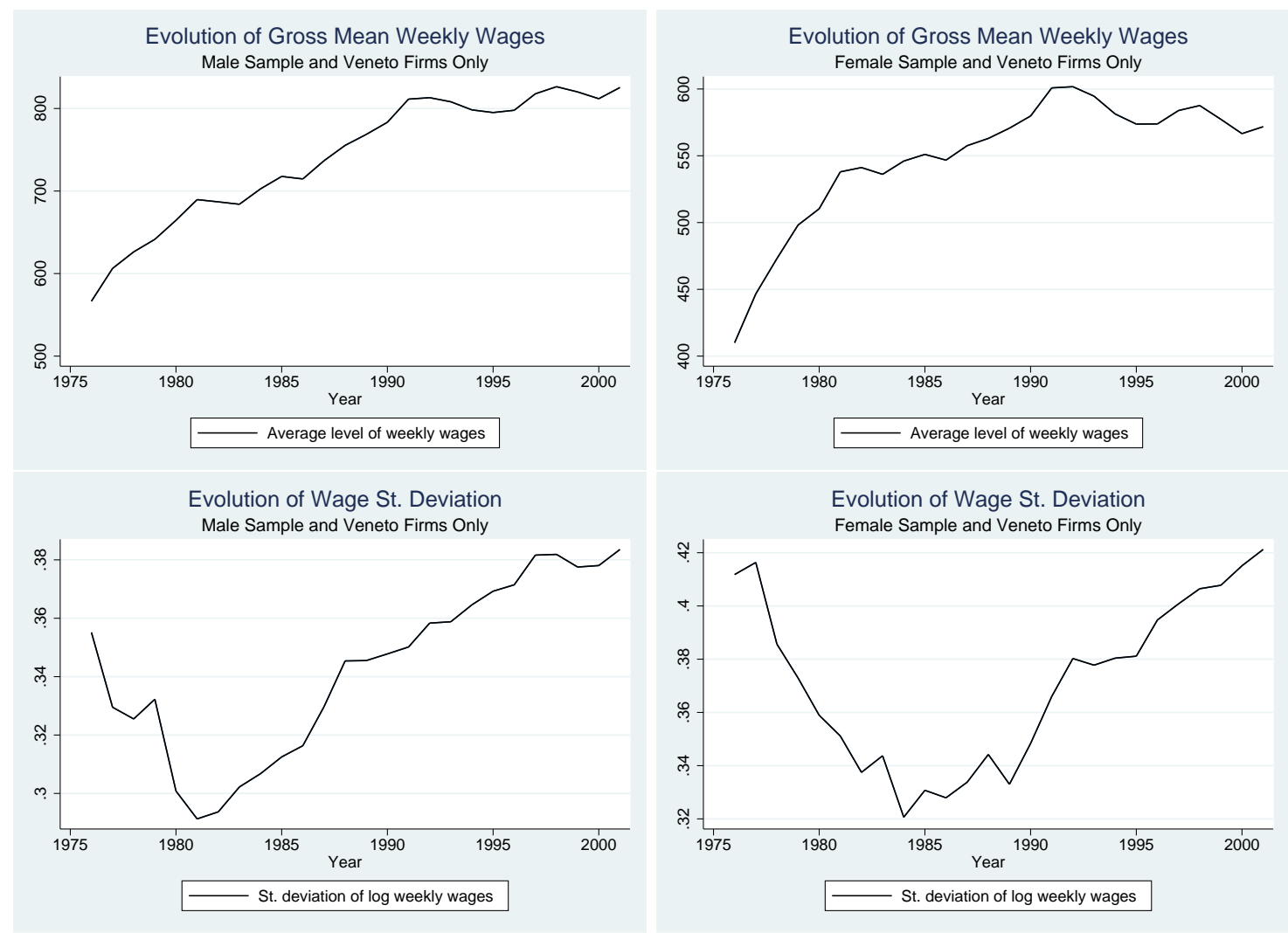